\title{
Physiotherapy Regimens in Esophagectomy and Gastrectomy: a Systematic Review and Meta-Analysis
}

\author{
Karina H. Tukanova, BSc, MMed ${ }^{1}$, Swathikan Chidambaram, BSc (hons), MBBS (hons), MRCS ${ }^{1}$, \\ Nadia Guidozzi, MB BCh ${ }^{2}$, George B. Hanna, PhD, FRCS ${ }^{1}$, Alison H. McGregor, PhD, MSc, MCSP ${ }^{1}$, and \\ Sheraz R. Markar, PhD, PhD, MSc, MA, MRCS ${ }^{1,3,4,5}$ \\ ${ }^{1}$ Department of Surgery and Cancer, Imperial College London, London, UK; ${ }^{2}$ Department of Surgery, University of the \\ Witwatersrand, Johannesburg, South Africa; ${ }^{3}$ Nuffield Department of Surgery, University of Oxford, Oxford, UK; \\ ${ }^{4}$ Department of Molecular Medicine and Surgery, Karolinska Institutet, Solna, Sweden; ${ }^{5}$ Division of Surgery, Department \\ of Surgery and Cancer, St Mary's Hospital, London, UK
}

\begin{abstract}
Background. Esophageal and gastric cancer surgery are associated with considerable morbidity, specifically postoperative pulmonary complications (PPCs), potentially accentuated by underlying challenges with malnutrition and cachexia affecting respiratory muscle mass. Physiotherapy regimens aim to increase the respiratory muscle strength and may prevent postoperative morbidity.

Objective. The aim of this study was to assess the impact of physiotherapy regimens in patients treated with esophagectomy or gastrectomy.

Methods. An electronic database search was performed in the MEDLINE, EMBASE, CENTRAL, CINAHL and Pedro databases. A meta-analysis was performed to assess the impact of physiotherapy on the functional capacity, incidence of PPCs and postoperative morbidity, in-hospital mortality rate, length of hospital stay (LOS) and healthrelated quality of life (HRQoL).

Results. Seven randomized controlled trials (RCTs) and seven cohort studies assessing prehabilitation totaling 960 patients, and five RCTs and five cohort studies assessing perior postoperative physiotherapy with 703 total patients, were included. Prehabilitation resulted in a lower incidence of postoperative pneumonia and morbidity (Clavien-Dindo
\end{abstract}

(C) The Author(s) 2021

First Received: 16 August 2021

Accepted: 11 November 2021;

Published Online: 27 December 2021

S. R. Markar, PhD, PhD, MSc, MA, MRCS

e-mail: s.markar@imperial.ac.uk score $\geq$ II). No difference was observed in functional exercise capacity and in-hospital mortality following prehabilitation. Meanwhile, peri- or postoperative rehabilitation resulted in a lower incidence of pneumonia, shorter LOS, and better HRQoL scores for dyspnea and physical functioning, while no differences were found for the QoL summary score, global health status, fatigue, and pain scores.

Conclusion. This meta-analysis suggests that implementing an exercise intervention may be beneficial in both the preoperative and peri- or postoperative periods. Further investigation is needed to understand the mechanism through which exercise interventions improve clinical outcomes and which patient subgroup will gain the maximal benefit.

\section{BACKGROUND}

Despite improvements in perioperative management, surgery for esophageal and gastric cancer is associated with considerable morbidity, particularly postoperative pulmonary complications (PPCs). PPCs include pneumonia and atelectasis, occur in about $20-40 \%$ of patients, ${ }^{1-3}$ and account for up to $55 \%$ of in-hospital deaths. ${ }^{4,5}$ The risk for PPCs development is multifactorial and includes both patient- and treatment-related factors. Open surgery is associated with significantly higher pain scores, which may interfere with respiratory mechanics and impede adequate mobilization, resulting in atelectasis and shallow breathing. ${ }^{6-10}$ Other intraoperative procedures that might contribute to PPCs include mechanical ventilation, patient positioning, and administration of sedatives. ${ }^{11-14}$ 
Following surgery, patients undergoing esophagogastrectomy often require chest drainage, contributing further to postoperative pain and altered respiratory mechanics. ${ }^{15,16}$

Preoperative factors also have an impact on the development of PPCs, including preoperative chemoradiotherapy. Although neoadjuvant chemoradiotherapy has led to a significant improvement in survival in esophageal and esophagogastric junction cancer, ${ }^{17}$ several studies suggest that the associated toxicity affects pulmonary function, causing a decline in diffusion capacity, and total lung and vital capacity. ${ }^{18}$ In addition to decreased exercise capacity following surgery, ${ }^{19}$ neoadjuvant chemotherapy is also associated with reduced physical fitness. ${ }^{20}$ Other predictive factors for severe complications include lower preoperative forced expiratory volume in 1 second $\left(\mathrm{FEV}_{1}\right),{ }^{21,22}$ decreased diffusion capacity, ${ }^{23}$ multiple comorbidities, and smoking. ${ }^{24}$ Physical activity levels also play an important role in the postoperative period, as patients with higher activity levels appeared to have a significantly lower risk for cancer recurrence, and had higher overall survival rates and better HRQoL scores compared with inactive participants. ${ }^{25}$ Finally, patients with gastrointestinal cancers often present with malnutrition and cachexia ${ }^{26-28}$ affecting respiratory muscle mass and strength, and subsequently increasing the risk for development of PPCs ${ }^{29,30}$ and poor functional capacity. ${ }^{31}$

Physiotherapy regimens such as early mobilization and breathing exercises aim to decrease the risk for PPCs by reversing atelectasis. ${ }^{32}$ There is some evidence that breathing exercises, both in the preoperative period ${ }^{32}$ and during postoperative recovery, ${ }^{33}$ decrease the incidence of PPCs in upper abdominal surgery. However, due to insufficient strong evidence, routine implementation of respiratory physiotherapy following abdominal surgery has not yet been implemented as a standard of care. ${ }^{32}$

To date, there has been no published meta-analysis assessing the effect of prehabilitation and peri- or postoperative physiotherapy regimens on postoperative mortality and morbidity in esophageal and gastric cancer surgery. The primary aim of this meta-analysis was to assess the impact of physiotherapy regimens on the incidence of major postoperative morbidity and in-hospital mortality. The secondary aims were to assess whether physiotherapy implementation decreases the length of hospital stay (LOS) and improves the functional exercise capacity and HRQoL.

\section{METHODS}

\section{Search Strategy}

A literature search was performed on the 18 February 2021 to identify relevant studies assessing physiotherapy regimens in patients undergoing esophagectomy or gastrectomy in the MEDLINE (Ovid), EMBASE (Ovid), Cochrane Central Register of Controlled Trials, CINAHL, and Physiotherapy Evidence (Pedro) databases. The search included the following index or free-text words, including synonyms and closely related words: '(o)esophagectomy', 'gastrectomy', 'physiotherapy', 'physical therapy', 'kinesi(o)therapy', 'muscle training', 'mobilization', and 'breathing techniques'. References of included articles were screened and a hand-search was performed to identify missing articles. The full electronic search strategy is available in electronic supplementary (ES) Table S1.

Two reviewers (KHT and NG) independently assessed the titles and abstracts for inclusion of relevant references. In the case of disagreement for inclusion, a third author (SRM) was consulted. Authors of the included studies were contacted to locate unpublished data.

The Preferred Reporting Items for Systematic Reviews and Meta-Analyses (PRISMA) ${ }^{33}$ guidelines were followed (ES Table S2).

\section{Study Selection}

Randomized controlled trials (RCTs), quasi-randomized trials, and cohort studies were included, implementing physiotherapy regimens in the pre-, peri- or postoperative periods for patients who have undergone esophagectomy or gastrectomy for malignant disease, either by open surgery or a minimally invasive approach.

Comparative studies were excluded if no outcome data were provided for the control or intervention groups. Studies were excluded if physiotherapy in the form of early mobilization was part of an enhanced recovery pathway and the impact of the pathway was assessed without evaluating the impact of the physiotherapy component.

\section{Outcome Measures}

The primary outcomes were the incidence of postoperative morbidity assessed using a Clavien-Dindo classification $^{34}$ (CDC) of 2 or higher, PPCs, and in-hospital mortality, while the secondary outcomes were assessment of the functional capacity via the 6-minute walking test (6MWT), LOS, and HRQoL.

\section{Quality Assessment of Selected Studies}

Two reviewers (KT and NG) assessed the quality of each included study by independently evaluating the risk of bias using the revised Cochrane risk-of-bias tool (RoB2) ${ }^{35}$ for the assessment of randomized trials and the NewcastleOttawa Scale (NOS) ${ }^{36}$ for the assessment of non-randomized studies. The RoB2 tool categorizes the risk of bias into 
'low', 'some concerns', or 'high' risk of bias. For the NOS scores ranging from 0 to 9 , we considered a score of $0-3$, 4-6, and 7-9 as low, moderate, or high-quality studies, respectively.

\section{Statistical Analysis}

Meta-analysis of the data was performed using the Review Manager version 5.3 software (Cochrane Collaboration, Oxford, UK). Both the fixed-effects and randomeffects models were considered in the analysis of the data and were the most appropriate models used to pool the results based on the distribution of the data. The standard heterogeneity test, the $I^{2}$ statistic, was used to assess the consistency of the effect sizes, which indicates the percentage of the variability in effect estimates because of true between-study variance rather than within-study variance. Statistical heterogeneity was graded as low, moderate, or high, with an $I^{2}$ of above $25 \%, 50 \%$, and $75 \%$, respectively. $^{37}$

\section{RESULTS}

\section{Literature Search Results}

The electronic database searches yielded 11,273 results. The database searches were complemented by a hand search, identifying eight articles through published systematic reviews and protocols. After removal of duplicates, 8048 publications were screened on the abstract. Subsequent screening of the full-text identified 33 relevant records, 17 of which assessed preoperative exercise programs (prehabilitation), while 16 studies assessed peri- or postoperative physiotherapy regimens (Fig. 1).

Among the studies assessing prehabilitation, seven were $\mathrm{RCTs}^{38-44}$ with an intervention group and a comparative control group, while one $\mathrm{RCT}^{45}$ compared two different types of interventions; the remaining nine publications were cohort studies. ${ }^{2,46-53}$ For the studies assessing periand postoperative physiotherapy, there were six RCTs ${ }^{54-59}$ comparing an intervention with a control group, and one study $^{60}$ compared two different types of physiotherapy. Among the cohort studies, eight studies ${ }^{61-68}$ had an intervention group and a comparative control, and one study ${ }^{69}$
FIG. 1 PRISMA flow chart. PRISMA Preferred Reporting Items for Systematic Reviews and Meta-Analyses
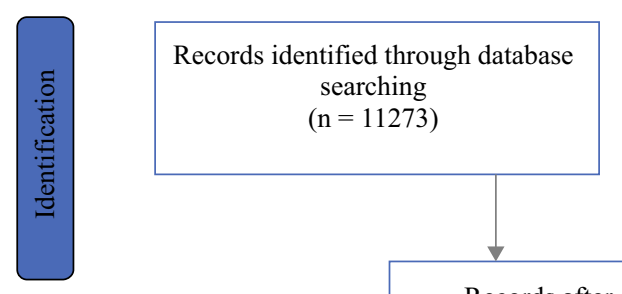
Additional records identified (other systematic reviews and hand search) $(\mathrm{n}=8)$

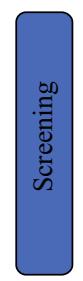

Records after duplicates removed $(n=8048)$

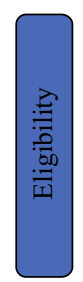

Full-text articles assessed for eligibility $(\mathrm{n}=102)$
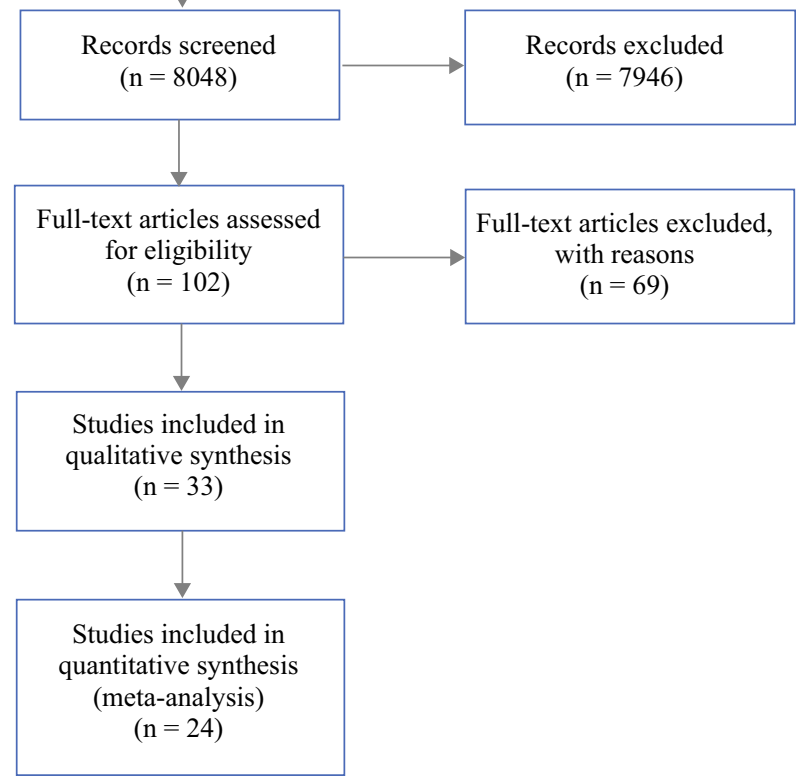

Full-text articles excluded, with reasons $(n=69)$
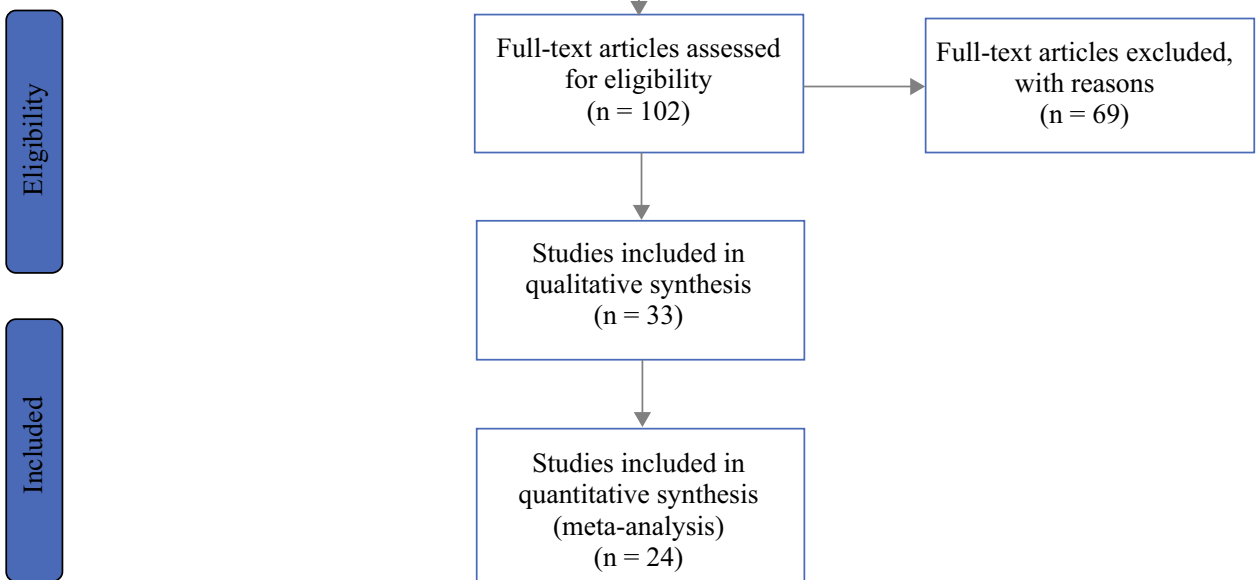

Studies included in litative synthesis (mitative synthesis $(\mathrm{n}=24)$ 


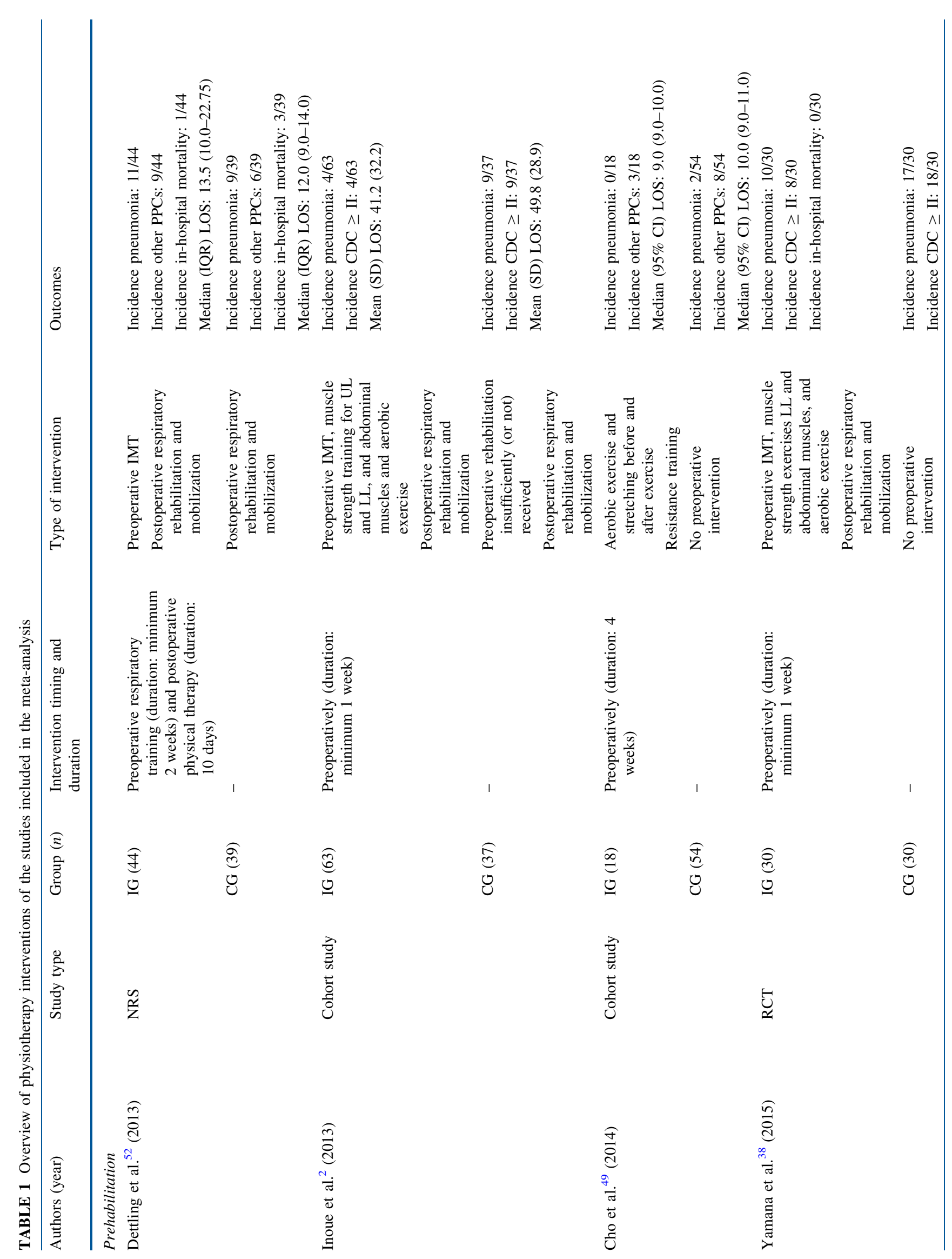




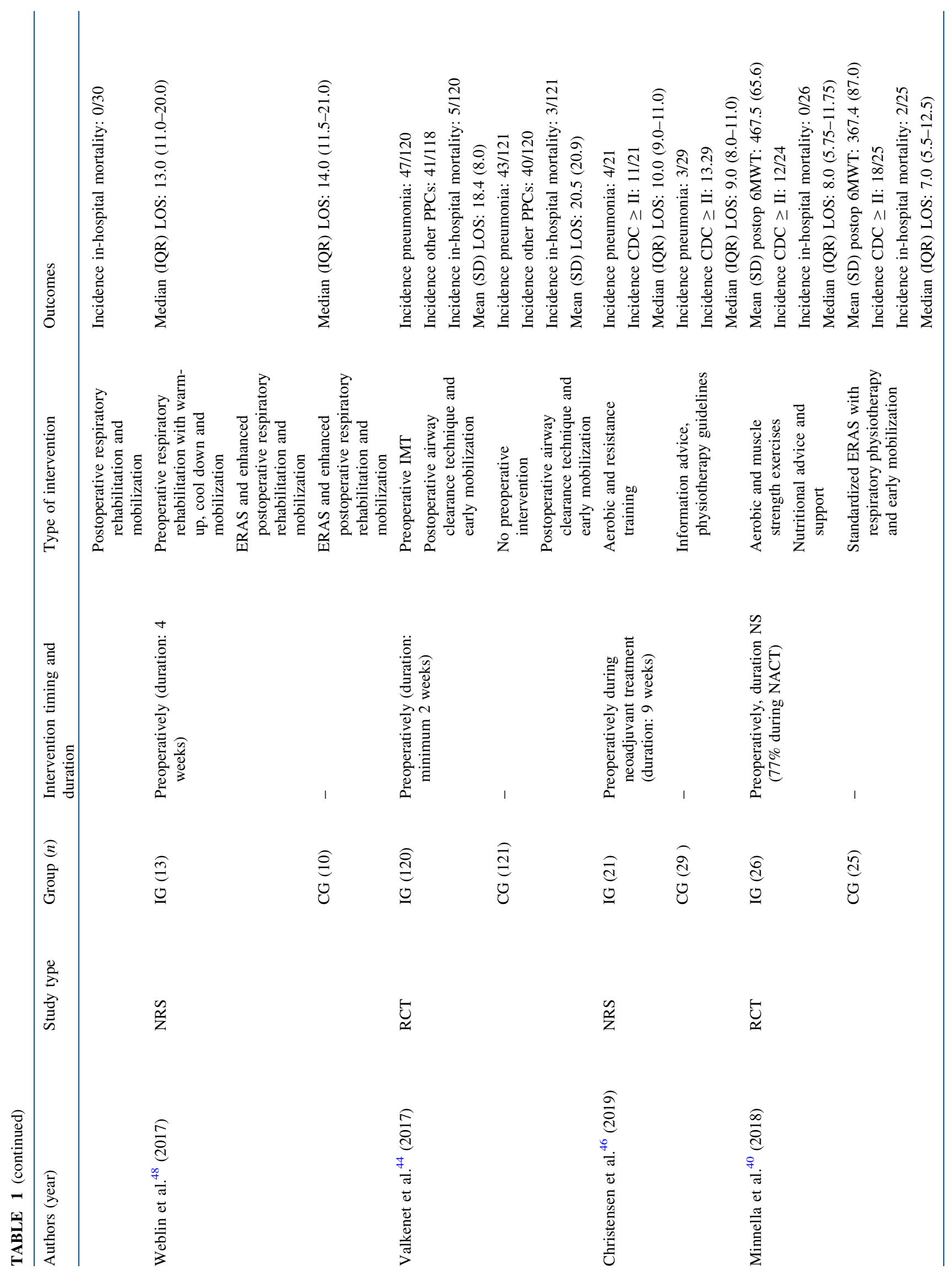




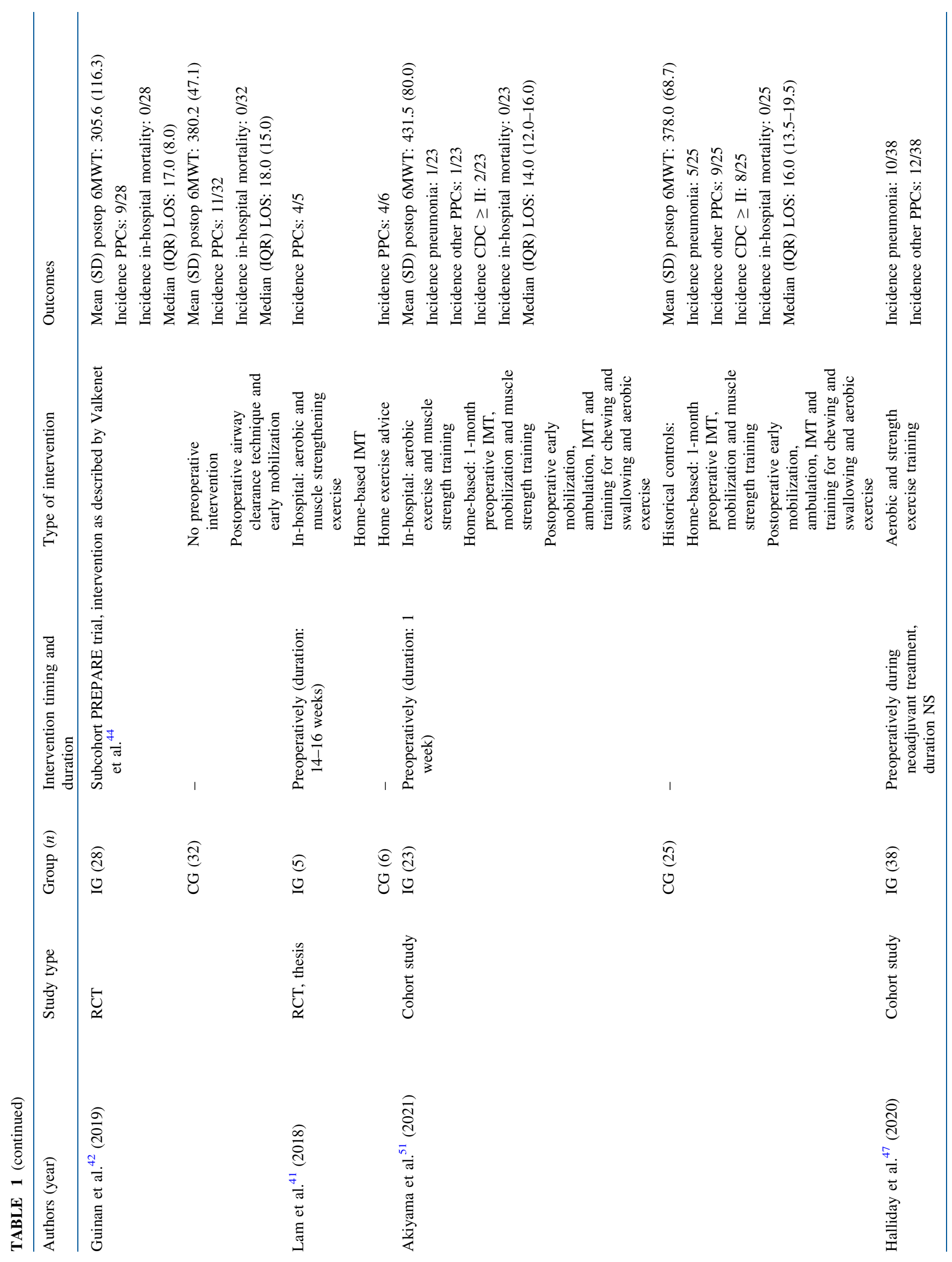




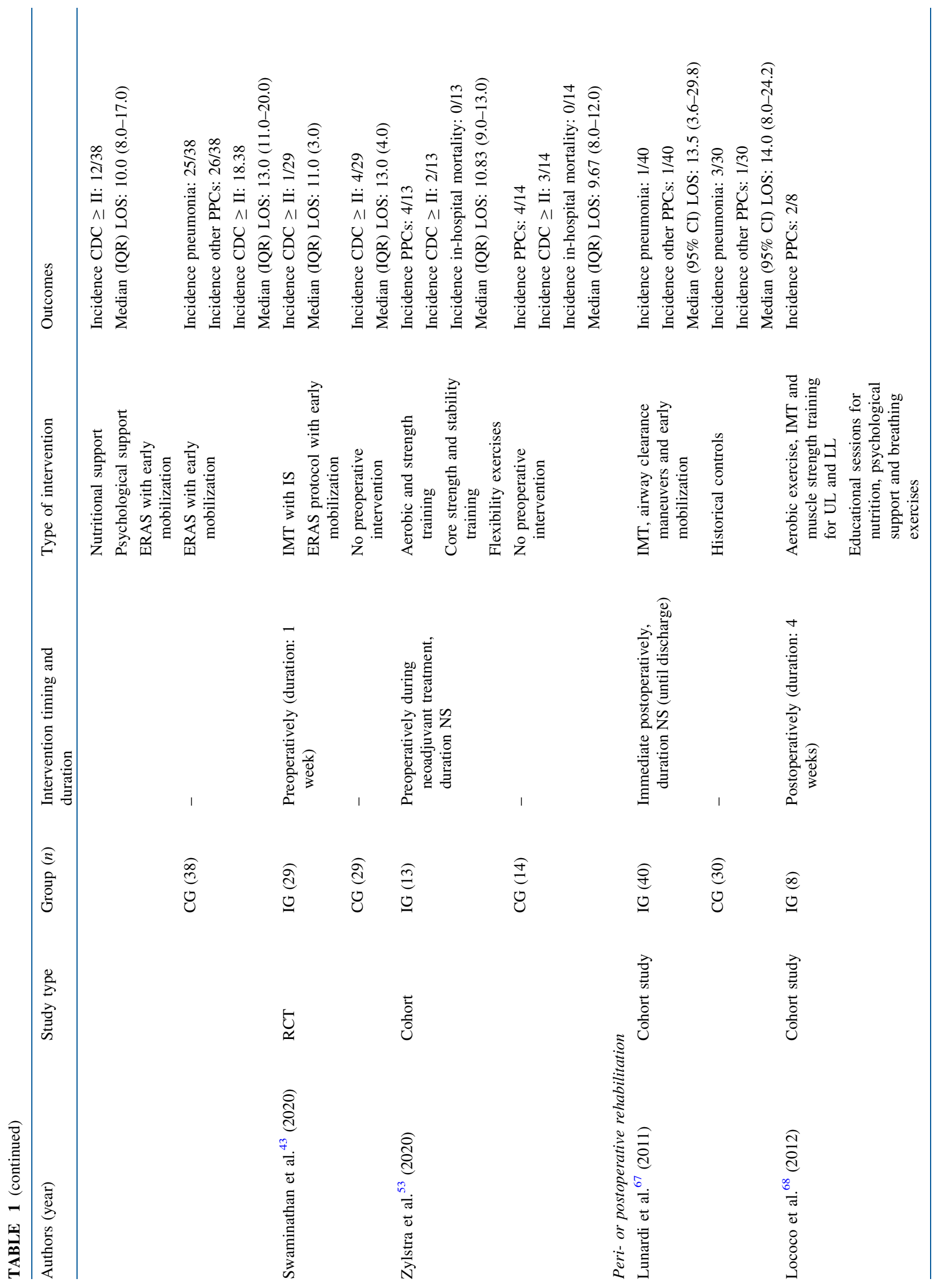




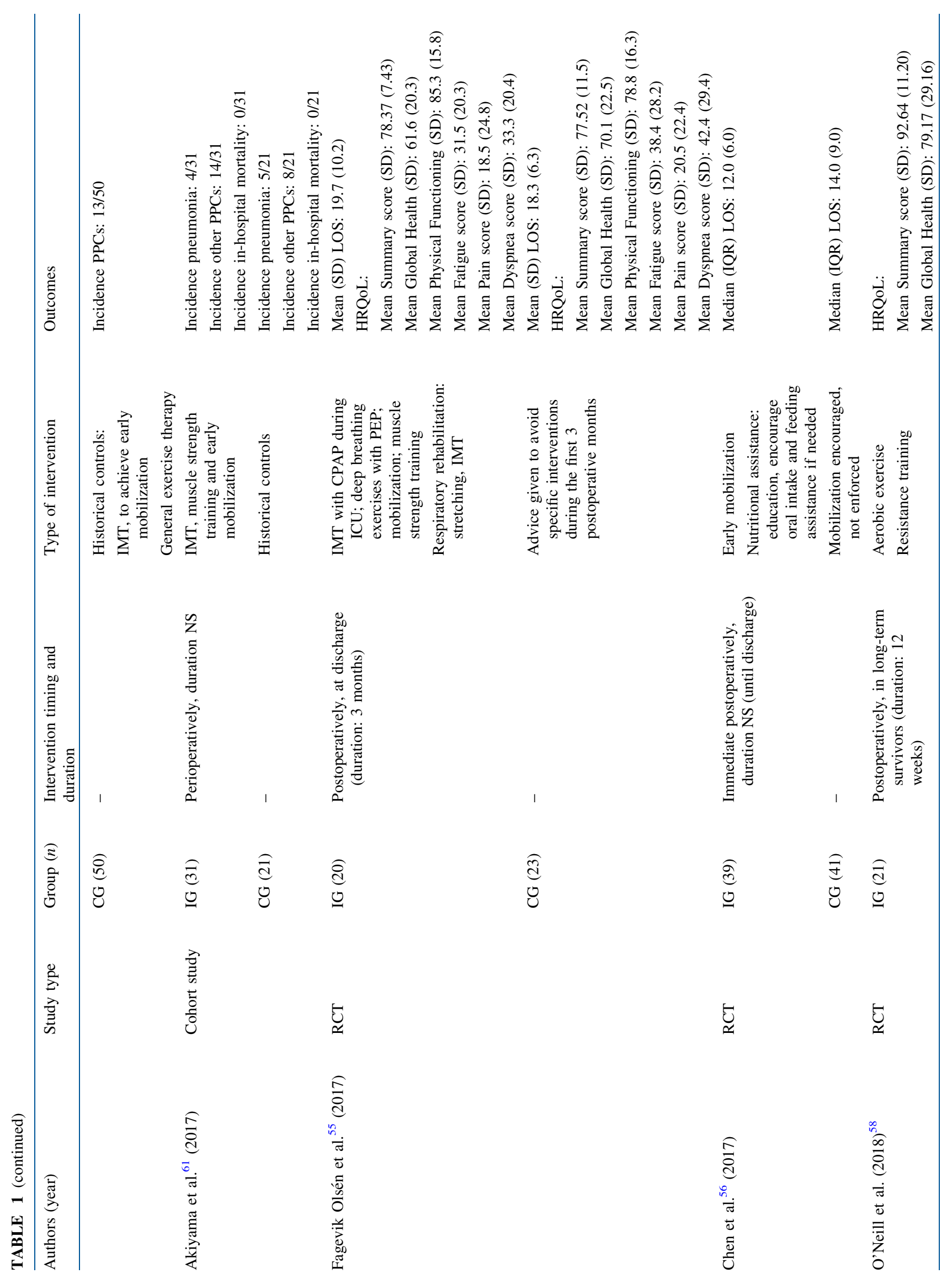




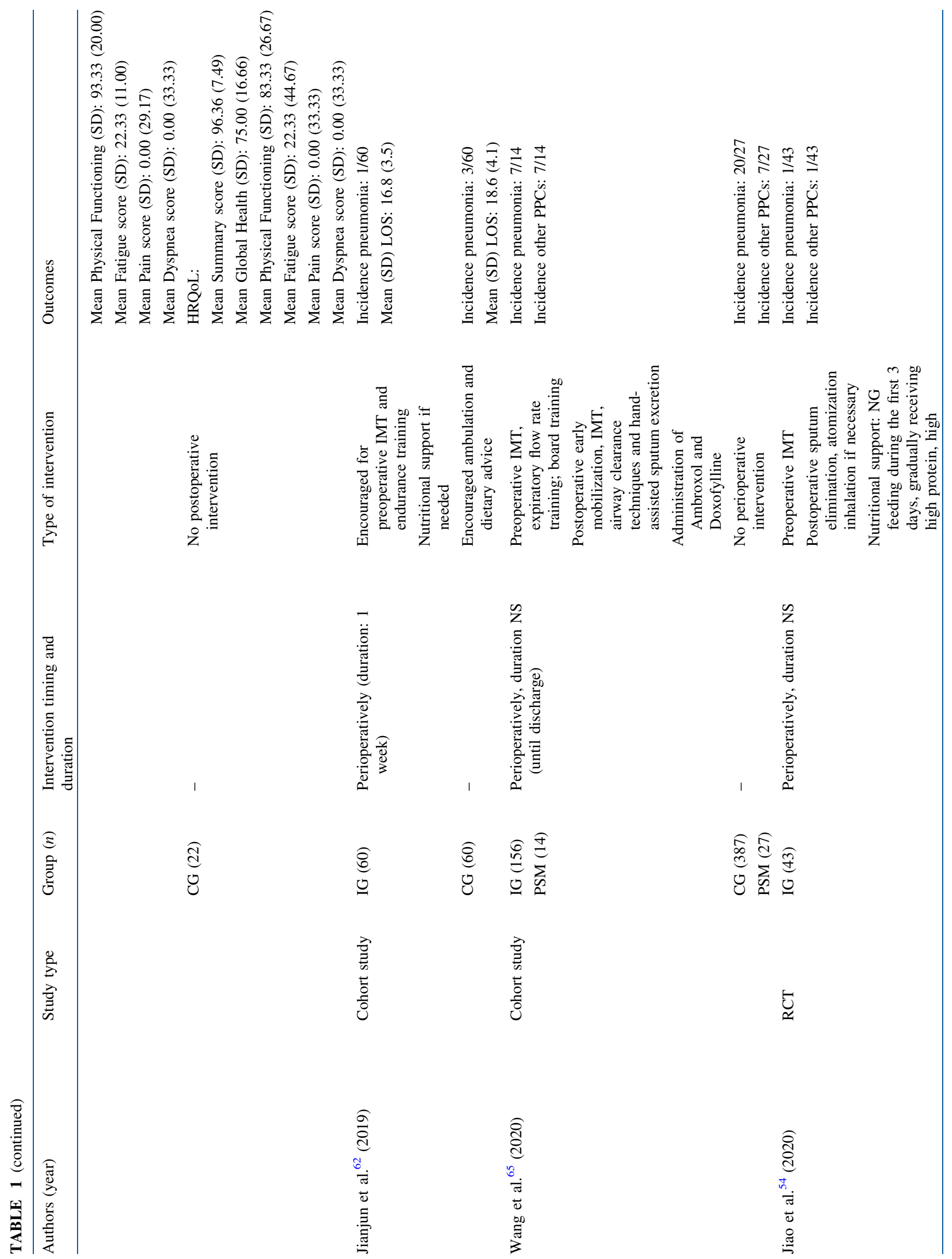




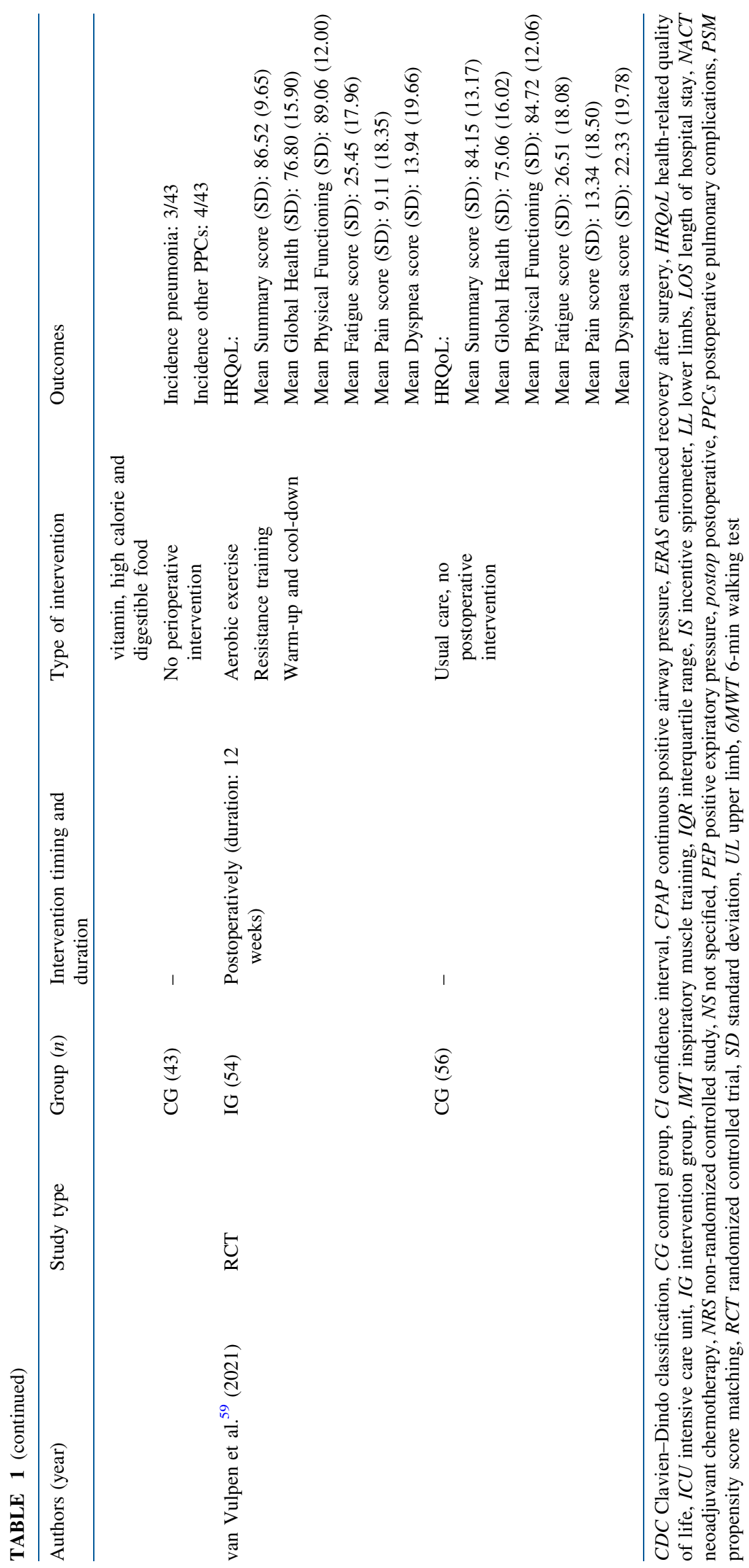




\section{(a)}

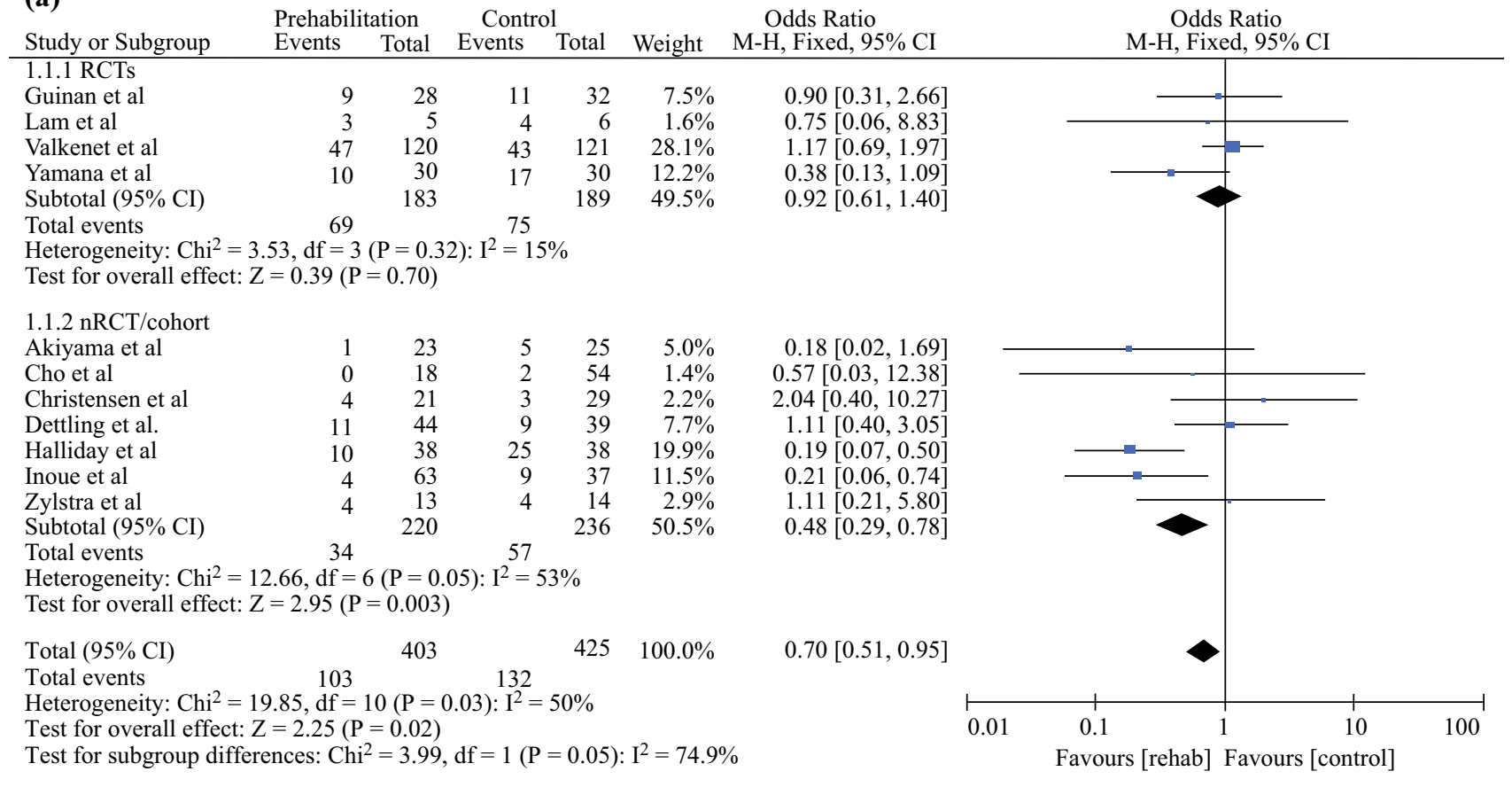

(b)

\begin{tabular}{|c|c|c|c|c|c|c|}
\hline \multirow[b]{2}{*}{ Study or Subgroup } & \multicolumn{2}{|c|}{ Prehabilitation } & \multicolumn{2}{|c|}{ Control } & \multirow{2}{*}{\multicolumn{2}{|c|}{ Weight }} \\
\hline & Events & Total & Events & Total & & \\
\hline \multicolumn{7}{|l|}{ 3.1.1 RCTs } \\
\hline \multirow{3}{*}{$\begin{array}{l}\text { Valkenet et al } \\
\text { Yamana et al } \\
\text { Subtotal }(95 \% \mathrm{CI}) \\
\text { Total events }\end{array}$} & 47 & 120 & 43 & & $31.0 \%$ & \\
\hline & 10 & 30 & 17 & 30 & $13.5 \%$ & \\
\hline & & 150 & & & $44.4 \%$ & \\
\hline \multicolumn{7}{|c|}{ Heterogeneity: $\mathrm{Chi}^{2}=3.50, \mathrm{df}=1(\mathrm{P}=0.06): \mathrm{I}^{2}=71 \%$} \\
\hline \multicolumn{7}{|l|}{$3.1 .2 \mathrm{nRCT} /$ cohort } \\
\hline Akiyama et al & 1 & 23 & 5 & 25 & $5.4 \%$ & \\
\hline Cho et al & 0 & 18 & 2 & 54 & $1.5 \%$ & \\
\hline Christensen et al & 4 & 21 & 3 & 29 & $2.4 \%$ & \\
\hline Dettling et al. & 11 & 44 & 9 & 39 & $8.5 \%$ & \\
\hline Halliday et al & 10 & 38 & 25 & 38 & $21.9 \%$ & \\
\hline Inoue et al & 4 & 63 & 9 & 37 & $12.6 \%$ & \\
\hline Zylstra et al & 4 & 13 & 4 & 14 & $3.2 \%$ & \\
\hline Subtotal $(95 \%$ CI $)$ & & 220 & & 236 & $55.6 \%$ & \\
\hline \multirow{3}{*}{\multicolumn{7}{|c|}{$\begin{array}{l}\text { Total events } \\
\text { Heterogeneity: } \mathrm{Chi}^{2}=12.66, \mathrm{df}=6(\mathrm{P}=0.05): \mathrm{I}^{2}=53 \% \\
\text { Test for overall effect: } \mathrm{Z}=2.95(\mathrm{P}=0.003)\end{array}$}} \\
\hline & & & & & & \\
\hline & & & & & & \\
\hline Total $(95 \% \mathrm{CI})$ & & 370 & & 387 & $100.0 \%$ & \\
\hline \multirow{2}{*}{\multicolumn{7}{|c|}{$\begin{array}{l}\text { Total events } \\
\text { Heterogeneity: } \mathrm{Chi}^{2}=19.64, \mathrm{df}=8(\mathrm{P}=0.01): \mathrm{I}^{2}=59 \%\end{array}$}} \\
\hline & & & & & & \\
\hline \multicolumn{7}{|c|}{ Test for overall effect: $\mathrm{Z}=2.28(\mathrm{P}=0.02)$} \\
\hline
\end{tabular}

FIG. 2 a Effect of prehabilitation on the incidence of pneumonia. b Effect of prehabilitation on the incidence of pneumonia, excluding the combined incidence of pneumonia and other PPCs. c Effect of peri- or postoperative rehabilitation on the incidence of pneumonia. d Effect of peri- or postoperative rehabilitation on the incidence of

assessed three groups consisting of two physiotherapy intervention groups and one comparative control group. An overview of interventions for studies included in the metaanalysis is shown in Table 1; a summary of the study characteristics of all studies is shown in ES Table S3, with a comprehensive summary of interventions for all studies provided in shown in ES Table S4. A summary of the
Odds Ratio -H, Fixed, 95\% CI $1.17[0.69,1.97]$
$0.38[0.13,1.09$ $0.38[0.59,1.48]$

$0.18[0.02,1.69$ $0.57[0.03,12.38$ $2.04[0.40,10.27$ $1.11[0.40,3.05$ $0.19[0.07,0.50$ $0.21[0.06,0.74$ $1.11=0.21,5.80$ $0.48[0.29,0.78]$

(1)

$0.68[0.49,0.95]$

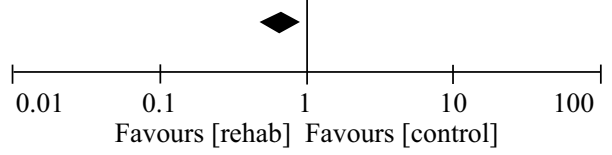

pneumonia, excluding the combined incidence of pneumonia and other PPCs. PPCs postoperative pulmonary complications, $M-H$ Mantel-Haenszel, $C I$ confidence interval, RCTs randomized controlled trials, $n R C T$ non-randomized controlled trials, $d f$ degrees of freedom

statistical method used for each analysis is presented in ES Table S5.

Finally, six RCTs ${ }^{38,40-44}$ and eight cohort studies ${ }^{2,46-49,51-53}$ assessing prehabilitation, and five RCTs $^{54-56,58,59}$ and five cohort studies ${ }^{61,62,65,67,68}$ assessing peri- or postoperative physiotherapy, were included in the 
(c)

Rehab Control

Odds Ratio

Odds Ratio

\begin{tabular}{lrrrrrr} 
Study or Subgroup & Events & Total & Events & Total & Weight & M-H, Fixed, 95\% CI \\
\hline 2.1 .1 RCTs & & & & & & \\
Jiao et al & 1 & 43 & 3 & 43 & $12.2 \%$ & $0.32[0.03,3.18]$ \\
Subtotal (95\% CI) & & 43 & & 43 & $12.2 \%$ & $0.32[0.03,3.18]$ \\
Total events & 1 & & 3 & & &
\end{tabular}

Heterogeneity: Not applicable

Test for overall effect: $\mathrm{Z}=0.98(\mathrm{P}=0.33)$

\subsection{2 nRCTs/cohort}

$\begin{array}{lrrrrrr}\text { Akiyama et al (2017) } & 4 & 31 & 5 & 21 & 21.7 \% & 0.47[0.11,2.03] \\ \text { Jianjun et al } & 1 & 60 & 3 & 60 & 12.3 \% & 0.32[0.03,3.19] \\ \text { Lococo et al } & 2 & 8 & 13 & 50 & 11.2 \% & 0.95[0.17,5.30] \\ \text { Lunardi et al } & 1 & 40 & 3 & 30 & 14.0 \% & 0.23[0.02,2.34] \\ \text { Wang et al } & 7 & 14 & 20 & 27 & 28.5 \% & 0.35[0.09,1.36] \\ \text { Subtotal (95\% CI) } & & 153 & & 188 & 87.8 \% & 0.43[0.20,0.93]\end{array}$

Total events $15 \quad 44$

Heterogeneity: $\mathrm{Chi}^{2}=1.26, \mathrm{df}=4(\mathrm{P}=0.87): \mathrm{I}^{2}=0 \%$

Test for overall effect: $\mathrm{Z}=2.15(\mathrm{P}=0.03)$

Total $(95 \% \mathrm{CI})$
$\begin{aligned} & \text { Total events } \quad 166 \\ & \text { Heterogeneity: } \mathrm{Chi}^{2}=1.32, \mathrm{df}=5(\mathrm{P}=0.93): \mathrm{I}^{2}=0 \%\end{aligned}$
Test for overall effect: $\mathrm{Z}=2.36(\mathrm{P}=0.02)$
Test for subgroup differences: $\mathrm{Chi}^{2}=0.06, \mathrm{df}=1(\mathrm{P}=0.80), \mathrm{I}^{2}=0 \%$

Test for subgroup differences: $\mathrm{Chi}^{2}=0.06, \mathrm{df}=1(\mathrm{P}=0.80), \mathrm{I}^{2}=0 \%$ M-H, Fixed, 95\% CI

(d)

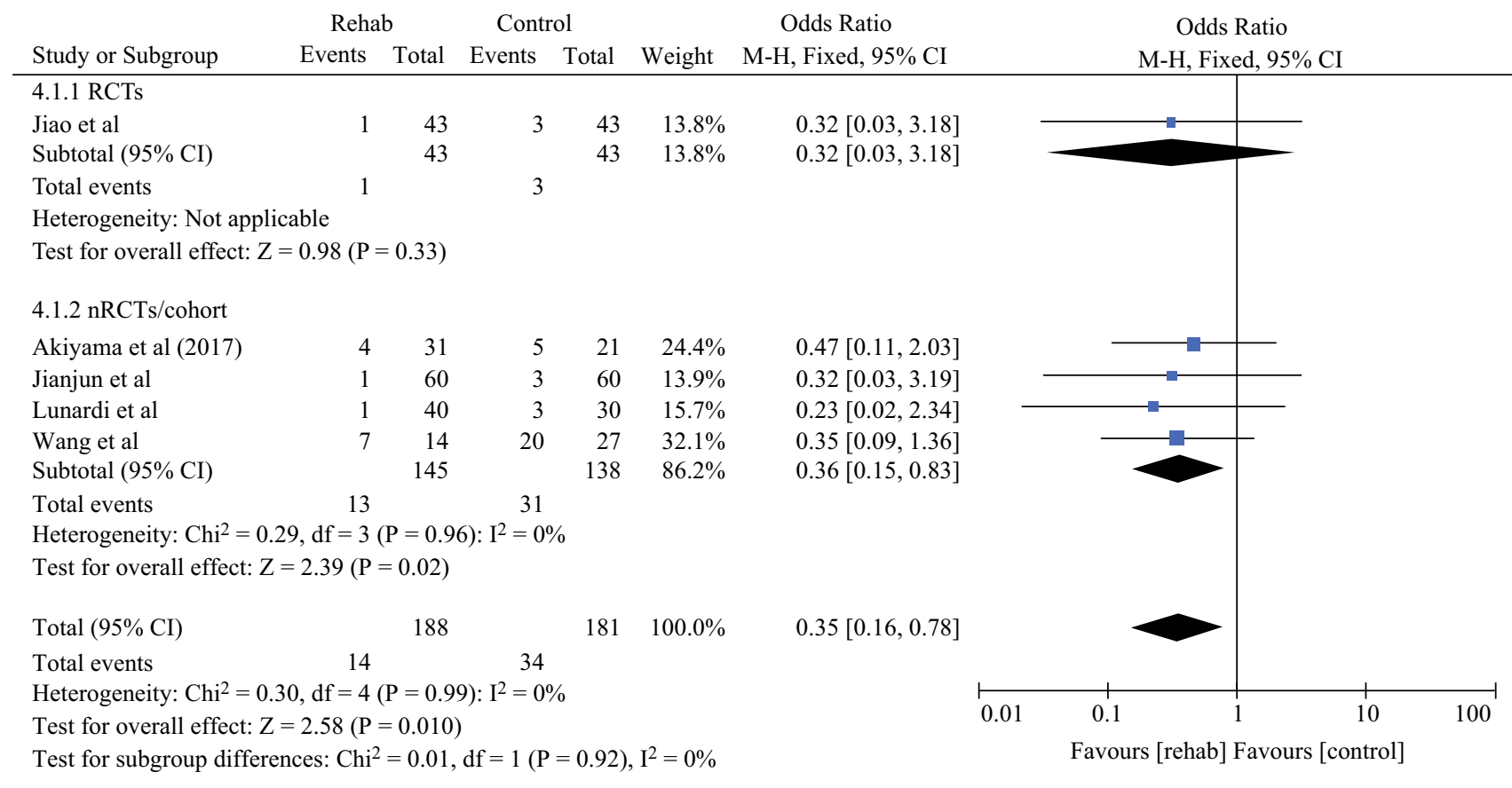

FIG. 2 continued

meta-analysis. Included and excluded studies are presented in ES Table S6 for each analysis.

\section{Functional Exercise Capacity}

Due to heterogeneity of outcome measures, a metaanalysis was performed for studies assessing exercise capacity following prehabilitation using the 6MWT. For 


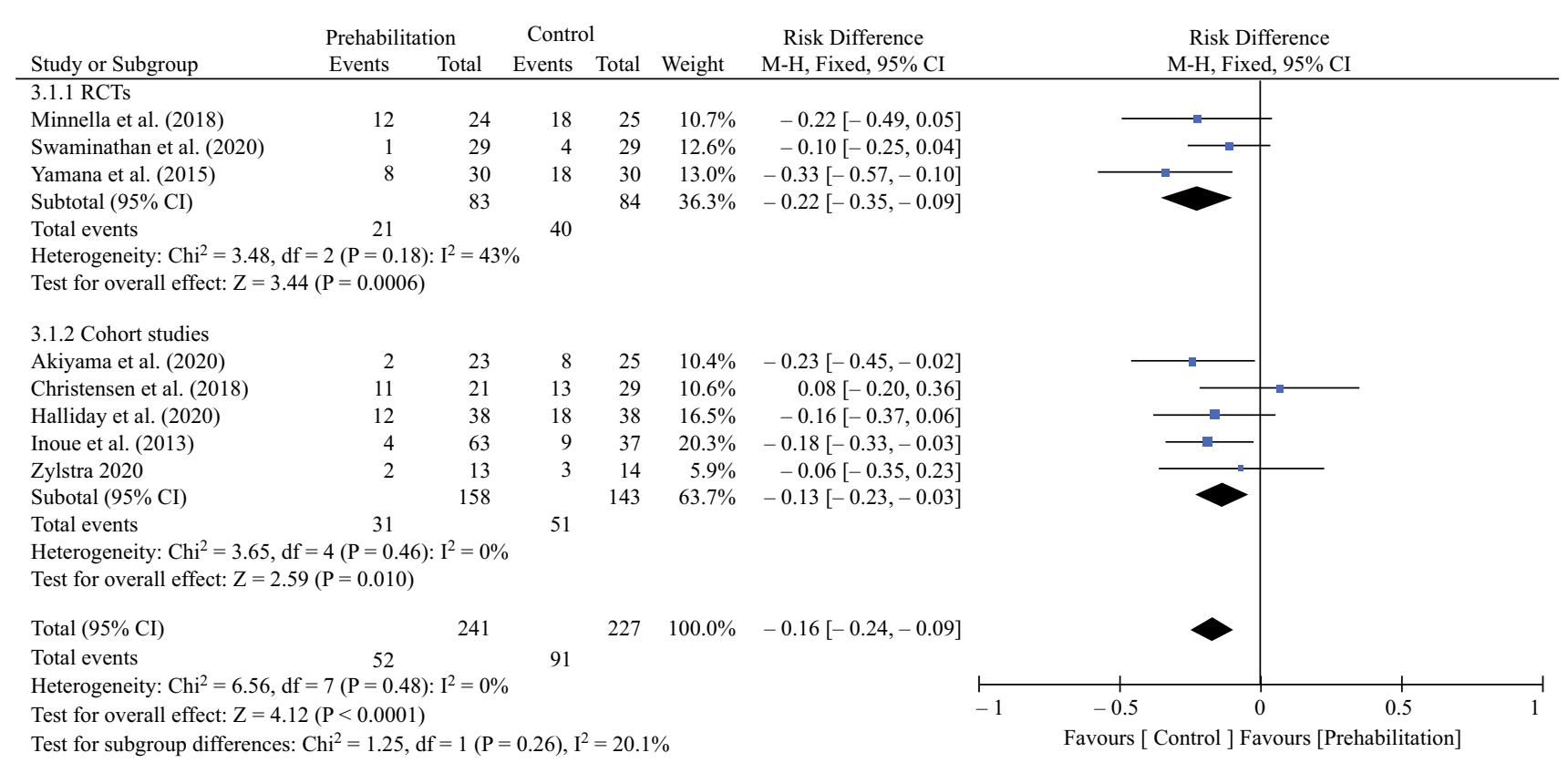

FIG. 3 Effect of prehabilitation on the incidence of postoperative morbidity (Clavien-Dindo grade II or higher). $M-H$ Mantel-Haenszel, $C I$ confidence interval, $R C T s$ randomized controlled trials, $d f$ degrees of freedom

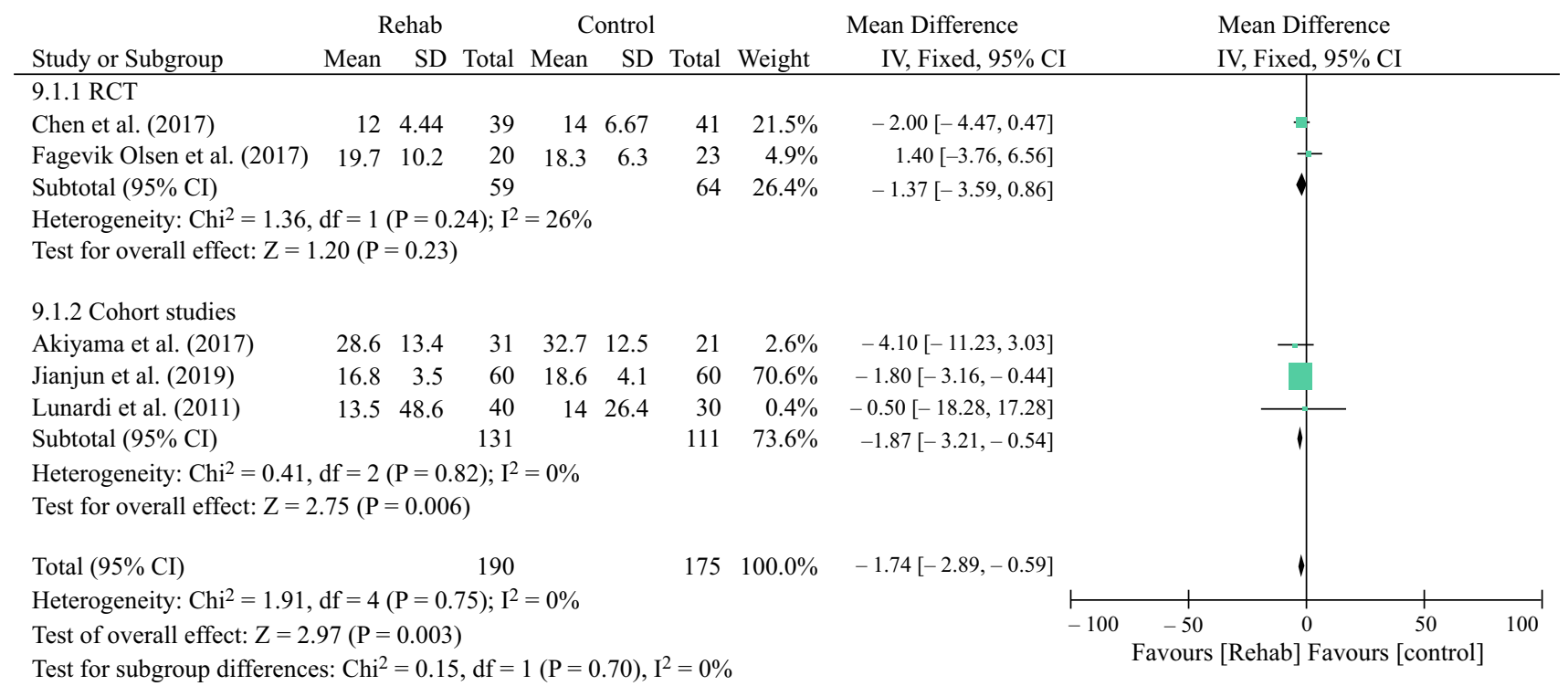

FIG. 4 Effect of peri- or postoperative rehabilitation on the LOS. $L O S$ length of hospital stay, $S D$ standard deviation, $I V$ inverse variance, $C I$ confidence interval, $R C T$ randomized controlled trial, $d f$ degrees of freedom

the final analysis, two RCTs ${ }^{40,42}$ and one cohort ${ }^{51}$ were included (ES Fig. S1). Change in functional capacity was reported from baseline to the postoperative period, with random-effects analysis showing no difference in the mean 6MWT between the two groups (pooled mean difference $26.70,95 \%$ confidence interval $[\mathrm{CI}]-73.10$ to 126.49 ; $p=0.60)$.

\section{Incidence of Pneumonia}

A meta-analysis was performed for all studies assessing the incidence of pneumonia following prehabilitation (Fig. 2a). Fixed-effects analysis demonstrated a significant difference between the two groups, with a lower incidence of pneumonia in patients receiving prehabilitation (pooled odds ratio [OR] $0.70,95 \%$ CI $0.51-0.95 ; p=0.02$ ). Further analysis was performed to assess the incidence of pneumonia, with the exclusion of studies providing the 


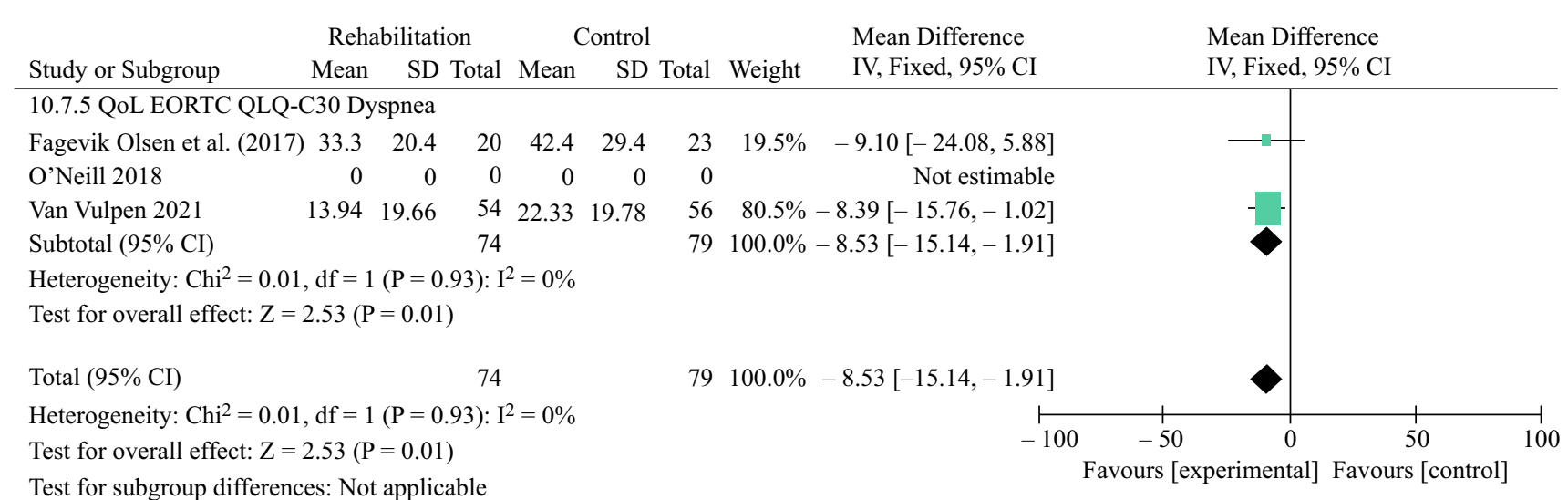

FIG. 5 Effect of peri- or postoperative rehabilitation on the EORTC QLQ-C30 Dyspnea. EORTC European Organisation for Research and Treatment of Cancer, $S D$ standard deviation, $I V$ inverse variance, $C I$ confidence interval, $d f$ degrees of freedom, $Q o L$ quality of life

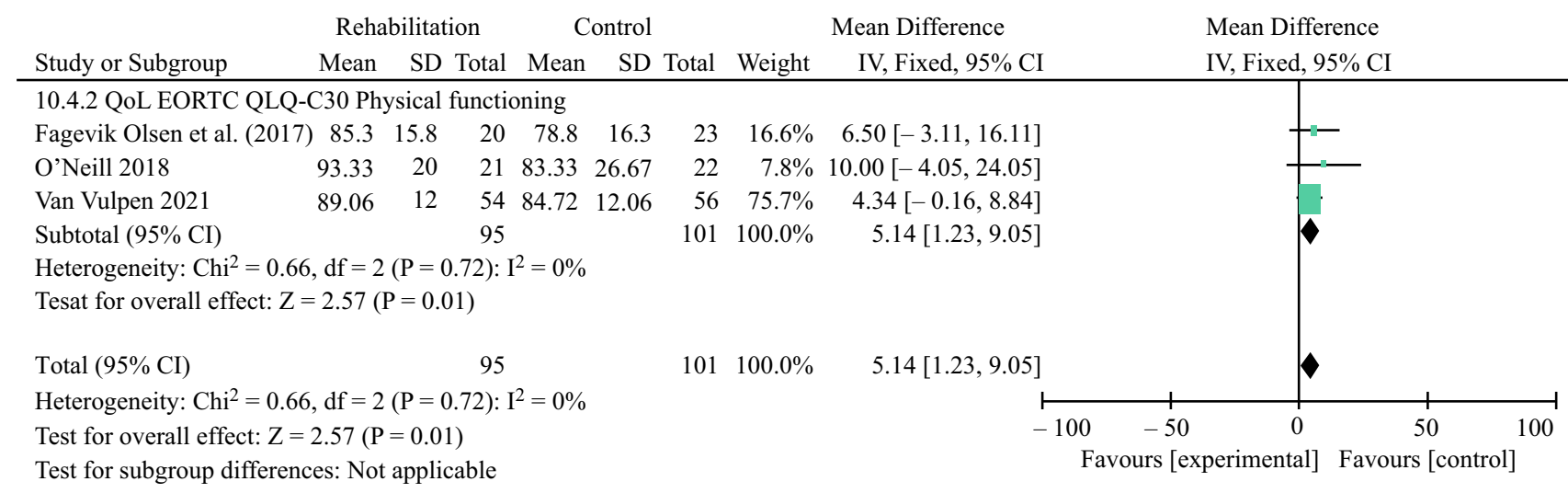

FIG. 6 Effect of peri- or postoperative rehabilitation on the EORTC QLQ-C30 Physical Functioning. EORTC European Organisation for Research and Treatment of Cancer, $S D$ standard deviation, $I V$ inverse variance, $C I$ confidence interval, $d f$ degrees of freedom, $Q o L$ quality of life

combined incidence of pneumonia and other PPCs (Fig. 2b). In agreement with previous findings, fixed-effects analysis showed a significantly lower incidence of pneumonia in patients receiving prehabilitation (pooled OR $0.68,95 \%$ CI $0.49-0.95 ; p=0.02$ ).

For peri- or postoperative rehabilitation, a meta-analysis was performed for all studies assessing the incidence of pneumonia (Fig. 2c), with fixed-effects analysis demonstrating a significant difference between the two groups, with a lower incidence of pneumonia in the rehabilitation group (pooled OR 0.42 , 95\% CI $0.20-0.86 ; p=0.02$ ). Further analysis was performed to assess the incidence of pneumonia, excluding the studies providing the combined incidence of pneumonia and other PPCs (Fig. 2d). Similarly, fixed-effects analysis demonstrated a significantly lower incidence of pneumonia in the rehabilitation group (pooled OR 0.35, 95\% CI 0.16-0.78; $p=0.01$ ).

\section{Incidence of Other Postoperative Pulmonary Complications (PPCs)}

A meta-analysis was performed for all studies assessing the incidence of other PPCs. Fixed-effects analyses showed no significant difference between the intervention and control groups following either prehabilitation (ES Fig. S2a; pooled OR $0.73,95 \%$ CI $0.51-1.05 ; p=0.09$ ) or rehabilitation (ES Fig. S2c; pooled OR 1.18, 95\% CI $0.60-2.32 ; p=0.63$ ).

For further analysis, articles that provided the combined incidence of other PPCs and pneumonia were excluded, thus only including studies that reported the incidence of other PPCs. In agreement with earlier findings, fixed-effects analyses showed no difference between the intervention and control groups for the incidence of other PPCs following prehabilitation (ES Fig. S2b; pooled OR $0.71,95 \%$ CI $0.48-1.05 ; p=0.09$ ) or rehabilitation (ES Fig. S2d; pooled OR 1.23, 95\% CI 0.59-2.58; $p=0.58$ ). 


\section{Postoperative Morbidity}

Fixed-effects analysis showed fewer complications in the prehabilitation group compared with the control group (risk difference $-0.16,95 \%$ CI -0.24 to -0.09 ; $p<0.0001$ ) (Fig. 3).

\section{Mortality}

Fixed-effects analysis was performed and showed no difference in the in-hospital mortality rates between the two groups (pooled OR $0.97,95 \%$ CI $0.31-3.03 ; p=0.95$ ) (ES Fig. S3).

\section{Length of Hospital Stay}

Given the high degree of statistical heterogeneity between studies, random-effects analysis was performed and showed no difference between the two groups (mean difference $-0.44,95 \% \mathrm{CI}-1.69$ to $0.82 ; p=0.50$ ) after prehabilitation (ES Fig. S4). There was no evidence of statistical heterogeneity between studies reporting the LOS after peri- or postoperative rehabilitation, therefore fixedeffects analysis showed shorter hospital stay in the rehabilitation group (mean difference $-1.74,95 \% \mathrm{CI}-2.89$ to $-0.59 ; p=0.003$ ) (Fig. 4).

\section{Health-Related Quality of Life}

A total of three RCTs ${ }^{55,58,59}$ were included in the final analysis. The 3-month outcomes were better after rehabilitation for dyspnea (mean difference -8.53 , 95\% CI -15.14 to 1.91 ) (Fig. 5) and physical functioning (mean difference 5.14, 95\% CI 1.23-9.05) (Fig. 6), while no significant difference was observed for the EORTC QLQC30 summary score (ES Fig. S5), global health (ES Fig. S6), fatigue (ES Fig. S7) and pain (ES Fig. S8) between the intervention and control groups.

\section{Methodological Quality of the Included Studies}

A summary of the risk of bias of the included RCTs. ${ }^{35}$ Overall, some concerns were present for the risk of bias assessment of the included RCTs. There were no studies that were considered as high risk of bias. The majority of the included RCTs applied an adequate randomization process with allocation concealment. Half of the studies did not report the method of missing data handling, and, for most studies, there was either inadequate blinding of outcome assessment or no information provided. An evaluation of the cohort studies included in the metaanalysis for the risk of bias is shown in ES Table S7. All but one cohort study received a score of least 6 , while seven cohort studies were awarded 7 stars or higher, indicating overall good quality.

\section{DISCUSSION}

In this meta-analysis, lower incidence of pneumonia and postoperative morbidity was observed in patients undergoing prehabilitation, however no significant differences were found for other outcomes. Peri- or postoperative rehabilitation resulted in a lower incidence of pneumonia, a shorter LOS and better HRQoL scores for dyspnea and physical functioning, while no effect was observed for the incidence of other PPCs, QoL summary score, global health status, fatigue, and pain scores.

Enhanced recovery after surgery (ERAS) is a multimodal approach aimed at promoting early recovery in patients undergoing major surgery, and commonly includes a physiotherapy component or early mobilization. ${ }^{70,71}$ These programs have been shown to reduce the risk for complications and decreased the LOS in colorectal surgery. ${ }^{72}$ Prehabilitation also consists of multiple components, such as preoperative exercise intervention, and nutritional and psychological support. Prehabilitation initially comprised of preoperative exercise training, which was developed to improve functional capacity. ${ }^{73,74}$ Nutritional support was subsequently implemented to optimize metabolic reserve preoperatively in order to adequately compensate for the catabolic response following surgery. ${ }^{75,76}$ Similar to findings observed in studies assessing ERAS programs, prehabilitation was shown to improve outcomes in patients undergoing major abdominal or thoracic surgery, with an increase in functional capacity, ${ }^{77,78}$ reduction in complication rates, and shortening in the LOS. ${ }^{79}$

Given the clinical importance of pulmonary complications, the incidence of PPCs was also assessed in this metaanalysis. Both prehabilitation and peri- or postoperative rehabilitation have been shown to reduce the risk for postoperative pneumonia, while no differences were observed for other PPC rates between patients receiving intervention and the control group. Interestingly, the magnitude of improvements in pneumonia and LOS were greater with peri- or postoperative rehabilitation than prehabilitation. There are several possible explanations for this, including the proximity in timing of the intervention to the measurement of the outcome, and, second, compliance with the intervention, with peri- and postoperative rehabilitation performed in the hospital setting. However, differences were observed between the RCTs and cohort studies, since RCTs showed no difference in the incidence of pneumonia following prehabilitation and rehabilitation. This could be explained by the low number of RCTs 
assessing prehabilitation and peri- or postoperative rehabilitation. For the analysis assessing the incidence of pneumonia after prehabilitation, the study by Valkenet et al. ${ }^{44}$ was given a greater weight than other RCTs, thus determining the outcome. The authors implemented inspiratory muscle training using an inspiratory loading device. The intervention was however home-based and only half of the participants $(54.2 \%)$ trained at least $80 \%$ of the planned sessions and $28 \%$ of the participants trained at least $80 \%$ of the sessions at the prescribed intensity. The study by Jiao et al. ${ }^{54}$ was the only RCT included in the analysis that assessed the impact of peri- or postoperative rehabilitation. The physiotherapy intervention consisted of preoperative deep breathing exercises with balloons and abdominal and pursed-lips breathing training followed by postoperative assisted sputum elimination. The exercises were commenced in the preoperative setting and continued in the immediate postoperative period throughout the hospital admission, with no specification of the duration and intensity of the training. Interestingly, both Valkenet et al. $^{44}$ and Jiao et al. ${ }^{54}$ reported significantly improved respiratory function in the intervention group compared with the control group, with a higher increase in respiratory muscle strength (maximal inspiratory muscle strength and inspiratory muscle endurance capacity), ${ }^{44}$ and higher respiratory function indices (forced vital capacity and peak expiratory flow), ${ }^{54}$ respectively.

HRQoL status was assessed in patients undergoing perior postoperative rehabilitation at 3 months following surgery. All three RCTs ${ }^{55,58,59}$ implemented a 12-week rehabilitation program, two ${ }^{58,59}$ of which implemented a program consisting of aerobic and resistance training, while the third study $^{55}$ included breathing exercises, strength training, and optimization of thoracic spine mobility. At 2 years after surgery, Fagevik Olsén et al. ${ }^{80}$ found clinically significant worse QoL scores for dyspnea, fatigue, diarrhea, and appetite loss. Another study presented similar findings, showing persistently worse QoL scores for physical functioning and dyspnea at 3 years after surgery. ${ }^{81}$ Moreover, pain around chest scars and reduced energy or activity tolerance were associated with long-term poor HRQoL. ${ }^{82}$ Lastly, the LOS did not differ in the prehabilitation group, while peri- or postoperative exercise intervention resulted into a significantly shorter LOS. Rehabilitation may therefore aid in earlier in-hospital recovery.

There are several limitations present in this meta-analysis. Due to the limited number of RCTs conducted, cohort studies were included in the analysis. For most RCTs, allocation was concealed, there was a low dropout rate following randomization, and the intervention and control groups were similar at baseline for most trials. However, several studies did not report handling of missing data and the reasons for dropout, and the majority of studies reported no blinding of outcome assessment. Several cohort studies used historical controls as a comparison group, consisting of patients who had undergone surgery before physiotherapy implementation. No subgroup analysis could be performed for the type of surgery, including the surgical approach (minimally invasive surgery [MIS] or open surgery), as some studies only provided the number of patients undergoing open surgery or MIS, while the number of patients undergoing either esophagectomy or gastrectomy within these subcohorts was not specified.

The short-term outcomes were assessed by well-defined measures, such as the CDC for surgical complications, and by reporting the mortality rates. The criteria for diagnosis of pneumonia were well-described in four studies, $2,38,44,52$ which were based on leukocyte count, presence of fever, sputum and chest X-Ray findings. However, the remaining studies reported the incidence of pneumonia or PPCs only. Perioperative rehabilitation was implemented in only a small number of studies, while postoperative rehabilitation was commonly commenced after discharge or in long-term survivors. Although a Clavien-Dindo score of 3 or higher is commonly considered for clinically complications, in this meta-analysis a cut-off at a score of 2 was used to assess the incidence of postoperative morbidity in order to include the incidence of pneumonia, classified as complications requiring pharmacological treatment (ClavienDindo score 2).

Patients with esophageal and gastric cancer commonly experience ongoing malnutrition after surgery and often report poor long-term physical functioning and ongoing respiratory symptoms. ${ }^{81,83-85}$ Physical activity levels were measured by obtaining the step count with an accelerometer. A total of three studies have reported physical activity, two of which assessed this outcome following prehabilitation, ${ }^{41,42}$ and only one study assessed this after rehabilitation in long-term survivors. ${ }^{58}$ The respiratory function was evaluated by estimating the respiratory volumes and by measuring the respiratory muscle pressure and endurance. A total of eight studies (four in the preoperative period $^{42,44,45,52}$ and four in the peri- or postoperative per$\operatorname{iod}^{54,55,60,68}$ ) reported the respiratory function, with only one study ${ }^{64}$ assessing the long-term outcomes. No metaanalysis could be performed due to different timing of measurements and the use of different parameters. This suggests that there is a lack of research assessing functional data in long-term survivorship undergoing rehabilitation. There was no standardized regimen as exercise interventions differed in timing and duration, and were either home-based or in-hospital, with or without supervision. The Borg scale was used to estimate the intensity of the intervention for a large number of studies. However, no standardized measure was available to compare all 
regimens. To date, there is an evident paucity of research comparing the impact the different components, intensity, and setting of physiotherapy in patients who have undergone esophagectomy or gastrectomy.

Finally, adherence was reported in the majority of studies included in the meta-analysis. For most studies, adherence was monitored by a physiotherapist, while a few studies implemented objective measures such as heart rate monitors, which could possibly improve the objectivity of adherence reporting.

\section{CONCLUSION}

The findings of this meta-analysis showed that implementation of exercise intervention may be beneficial in both the preoperative and peri- or postoperative periods. The next steps of the investigation are to identify which components, or pre-habilitation and peri- and postoperative rehabilitation, have the greatest impact on the clinical outcomes. Furthermore, clearly the Achilles heel to prehabilitation and rehabilitation is patient compliance; more research is needed to understand the human factors and patient barriers around complications to these regimens, to ensure the long-term clinical effectiveness.

FUNDING Sheraz Markar is funded by the National Institute of Health Research (NIHR). The views expressed are those of the authors and not necessarily those of the National Health Service, the NIHR, or the Department of Health.

\section{DECLARATIONS}

CONFLICT OF INTEREST Karina H. Tukanova, Swathikan Chidambaram, Nadia Guidozzi, George B. Hanna, Alison H. McGregor, and Sheraz R. Markar declare no conflicts of interest.

Supplementary Information The online version contains supplementary material available at https://doi.org/10.1245/s10434021-11122-7.

OPEN ACCESS This article is licensed under a Creative Commons Attribution 4.0 International License, which permits use, sharing, adaptation, distribution and reproduction in any medium or format, as long as you give appropriate credit to the original author(s) and the source, provide a link to the Creative Commons licence, and indicate if changes were made. The images or other third party material in this article are included in the article's Creative Commons licence, unless indicated otherwise in a credit line to the material. If material is not included in the article's Creative Commons licence and your intended use is not permitted by statutory regulation or exceeds the permitted use, you will need to obtain permission directly from the copyright holder. To view a copy of this licence, visit http://creativecommons. org/licenses/by/4.0/.

\section{REFERENCES}

1. Ferguson MK, Celauro AD, Prachand V. Prediction of major pulmonary complications after esophagectomy. Ann Thorac Surg. 2011;91(5):1494-501. https://doi.org/10.1016/j.athoracsur.2010. 12.036.

2. Inoue $\mathrm{J}$, Ono $\mathrm{R}$, Makiura $\mathrm{D}$, et al. Prevention of postoperative pulmonary complications through intensive preoperative respiratory rehabilitation in patients with esophageal cancer. Dis Esophagus. 2013;26(1):68-74. https://doi.org/10.1111/j.1442-20 50.2012.01336.x.

3. Atkins BZ, Shah AS, Hutcheson KA, et al. Reducing hospital morbidity and mortality following esophagectomy. Ann Thorac Surg. 2004;78(4):1170-6. https://doi.org/10.1016/j.athoracsur.20 04.02.034.

4. Law S, Wong K-H, Kwok K-F, Chu K-M, Wong J. Predictive factors for postoperative pulmonary complications and mortality after esophagectomy for cancer. Ann Surg. 2004;240(5):791-800. https://doi.org/10.1097/01.sla.0000143123.24556.1c.

5. Ferguson MK, Durkin AE. Preoperative prediction of the risk of pulmonary complications after esophagectomy for cancer. $J$ Thorac Cardiovasc Surg. 2002;123(4):661-9. https://doi.org/10. 1067/mtc.2002.120350.

6. Gerner P. Postthoracotomy pain management problems. Anesthesiol Clin. 2008;26(2):355-67. https://doi.org/10.1016/j.anclin. 2008.01.007.

7. Rogers ML, Duffy JP. Surgical aspects of chronic post-thoracotomy pain. Eur J Cardio-Thorac Surg. 2000;18(6):711-6. h ttps://doi.org/10.1016/S1010-7940(00)00569-8.

8. Cook, D, Simons D. Neuromuscular Blockade. Treasure Island, F): StatPearls Publishing. Available at: https://doi.org/https://w ww.ncbi.nlm.nih.gov/books/NBK538301/.

9. Gammon MD, Schoenberg JB, Ahsan H, et al. Tobacco, alcohol, and socioeconomic status and adenocarcinomas of the esophagus and gastric cardia. J Natl Cancer Inst. 1997;89(17):1277-84. h ttps://doi.org/10.1093/jnci/89.17.1277.

10. Kirmeier E, Eriksson LI, Lewald H, et al. Post-anaesthesia pulmonary complications after use of muscle relaxants (POPULAR): a multicentre, prospective observational study. Lancet Respir Med. 2019;7(2):129-40. https://doi.org/10.1016/S2213-2600(18) 30294-7.

11. Saraswat V. Effects of anaesthesia techniques and drugs on pulmonary function. Indian J Anaesth. 2015;59(9):557-64. http s://doi.org/10.4103/0019-5049.165850.

12. Tremblay LN, Slutsky AS. Ventilator-induced lung injury: from the bench to the bedside. Intensive Care Med. 2006;32(1):24-33. https://doi.org/10.1007/s00134-005-2817-8.

13. Lumb $\mathrm{AB}$. Why do patients need extra oxygen during a general anaesthetic? BJA Educ. 2019;19(2):37-9. https://doi.org/10.1016/ j.bjae.2018.11.005.

14. Davies OJ, Husain T, Stephens RCM. Postoperative pulmonary complications following non-cardiothoracic surgery. BJA Educ. 2017;17(9):295-300. https://doi.org/10.1093/bjaed/mkx012.

15. Dajczman E, Gordon A, Kreisman H, Wolkove N. Long-term postthoracotomy pain. Chest. 1991;99(2):270-4. https://doi.org/ 10.1378/chest.99.2.270.

16. McAnena OJ, Rogers J, Williams NS. Right thoracoscopically assisted oesophagectomy for cancer. $\mathrm{Br} J$ Surg. 1994;81(2):236-8.

17. Biere SS, Maas KW, Bonavina L, et al. Traditional invasive versus minimally invasive esophagectomy: a multi-center, randomized trial (TIME-trial). BMC Surg. 2011;11:2. https://doi.org/ 10.1186/1471-2482-11-2.

18. Biere SSAY, van Berge Henegouwen MI, Maas KW, et al. Minimally invasive versus open oesophagectomy for patients 
with oesophageal cancer: a multicentre, open-label, randomised controlled trial. Lancet. 2012;379(9829):1887-92. https://doi.org/ 10.1016/S0140-6736(12)60516-9.

19. Inoue $T$, Ito $S$, Ando $M$, et al. Changes in exercise capacity, muscle strength, and health-related quality of life in esophageal cancer patients undergoing esophagectomy. BMC Sport Sci Med Rehabil. 2016;8(1):34. https://doi.org/10.1186/s13102-016-0060$\mathrm{y}$.

20. Restrepo RD, Braverman J. Current challenges in the recognition, prevention and treatment of perioperative pulmonary atelectasis. Expert Rev Respir Med. 2015;9(1):97-107. https://doi.org/10.15 86/17476348.2015.996134.

21. Landreneau RJ, Hazelrigg SR, Mack MJ, et al. Postoperative pain-related morbidity: video-assisted thoracic surgery versus thoracotomy. Ann Thorac Surg. 1993;56(6):1285-9. https://doi. org/10.1016/0003-4975(93)90667-7.

22. Markar SR, Ni M, Gisbertz SS, et al. Implementation of minimally invasive esophagectomy from a randomized controlled trial setting to national practice. J Clin Oncol. 2020;38(19):2130-9. h ttps://doi.org/10.1200/JCO.19.02483.

23. Goense L, Meziani J, Bülbül M, Braithwaite SA, van Hillegersberg R, Ruurda JP. Pulmonary diffusion capacity predicts major complications after esophagectomy for patients with esophageal cancer. Dis esophagus. 2019. https://doi.org/10.1093/dote/d oy082.

24. Akaishi T, Kaneda I, Higuchi N, et al. Thoracoscopic en bloc total esophagectomy with radical mediastinal lymphadenectomy. J Thorac Cardiovasc Surg. 1996;112(6):1533-40. https://doi.org/ 10.1016/S0022-5223(96)70012-0.

25. Klevebro F, Elliott JA, Slaman A, et al. Cardiorespiratory comorbidity and postoperative complications following esophagectomy: a European multicenter cohort study. Ann Surg Oncol. 2019;26(9):2864-73. https://doi.org/10.1245/s10434-01907478-6.

26. Petersson J, Glenny RW. Gas exchange and ventilation-perfusion relationships in the lung. Eur Respir J. 2014;44(4):1023-41. h ttps://doi.org/10.1183/09031936.00037014.

27. Kneyber MCJ, Zhang H, Slutsky AS. Ventilator-induced lung injury. Similarity and differences between children and adults. Am J Respir Crit Care Med. 2014;190(3):258-65. https://doi.org/ 10.1164/rccm.201401-0168CP.

28. Gelb AW, Southorn P, Rehder K. Effect of general anaesthesia on respiratory function. Lung. 1981;159(1):187-98. https://doi.org/ 10.1007/BF02713915.

29. Sasaki N, Meyer MJ, Eikermann M. Postoperative respiratory muscle dysfunction: pathophysiology and preventive strategies. Anesthesiology. 2013;118(4):961-78. https://doi.org/10.1097/AL N.0b013e318288834f.

30. Drummond GB. The abdominal muscles in anaesthesia and after surgery. BJA Br J Anaesth. 2003;91(1):73-80. https://doi.org/10. 1093/bja/aeg 145 .

31. Pérez-Cruz E, Camacho-Limas CP. Association of nutritional status and functional capacity in gastrointestinal cancer patients. Gac Med Mex. 2017;153(5):575-80. https://doi.org/10.24875/G MM.17002776 (in Spanish).

32. Pasquina P, Tramér MR, Granier J-M, Walder B. Respiratory physiotherapy to prevent pulmonary complications after abdominal surgery: a systematic review. Chest. 2006;130(6):1887-99. h ttps://doi.org/10.1378/chest.130.6.1887.

33. Page MJ, McKenzie JE, Bossuyt PM, et al. The PRISMA 2020 statement: an updated guideline for reporting systematic reviews. BMJ. 2021;372:n71. https://doi.org/10.1136/bmj.n71.

34. Clavien PA, Barkun J, de Oliveira ML, et al. The Clavien-Dindo classification of surgical complications: five-year experience. Ann Surg. 2009;250(2):187-96. https://doi.org/10.1097/SLA.0b013e3 $181 \mathrm{~b} 13 \mathrm{ca} 2$.
35. Sterne JAC, Savović J, Page MJ, et al. RoB2: a revised tool for assessing risk of bias in randomised trials. BMJ. 2019;366:14898. https://doi.org/10.1136/bmj.14898.

36. Wells GA, Shea B, O'Connell D, Peterson J, Welch V, Losos M, Tugwell P. The Newcastle-Ottawa Scale (NOS) for assessing the quality of nonrandomised studies in meta-analyses. 2008. Available at: https://doi.org/http://www.ohri.ca/programs/clinica 1_epidemiology/oxford.asp. Accessed 8 Apr 2021.

37. Higgins JPT, Thompson SG, Deeks JJ, Altman DG. Measuring inconsistency in meta-analyses. BMJ. 2003;327(7414):557-60. h ttps://doi.org/10.1136/bmj.327.7414.557.

38. Yamana I, Takeno S, Hashimoto T, Maki K, Shibata R, Shiwaku $\mathrm{H}$, et al. Randomized controlled study to evaluate the efficacy of a preoperative respiratory rehabilitation program to prevent postoperative pulmonary complications after esophagectomy. Dig Surg. 2015;32(5):331-7. https://doi.org/10.1159/000434758.

39. Xu Y-J, Cheng JC-H, Lee J-M, Huang P-M, Huang G-H, Chen CC-H. A walk-and-eat intervention improves outcomes for patients with esophageal cancer undergoing neoadjuvant chemoradiotherapy. Oncologist. 2015;20(10):1216-22. https://d oi.org/10.1634/theoncologist.2015-0178.

40. Minnella EM, Awasthi R, Loiselle S-E, Agnihotram RV, Ferri LE, Carli F. Effect of exercise and nutrition prehabilitation on functional capacity in esophagogastric cancer surgery: a randomized clinical trial. JAMA Surg. 2018;153(12):1081-9. h ttps://doi.org/10.1001/jamasurg.2018.1645.

41. Lam S. Physical activity in the aetiology and preoperative management of oesophageal adenocarcinoma. $\mathrm{PhD}$ thesis, University of East Anglia, Norwich. 2018.

42. Guinan EM, Forde C, O'Neill L, et al. Effect of preoperative inspiratory muscle training on physical functioning following esophagectomy. Dis Esophagus. 2019;32(2):doy091. https://doi. org/10.1093/dote/doy091.

43. Swaminathan N, Kundra P, Ravi R, Kate V. ERAS protocol with respiratory prehabilitation versus conventional perioperative protocol in elective gastrectomy - a randomized controlled trial. Int J Surg. 2020;81:149-57. https://doi.org/10.1016/j.ijsu.2020. 07.027.

44. Valkenet K, Trappenburg JCA, Ruurda JP, et al. Multicentre randomized clinical trial of inspiratory muscle training versus usual care before surgery for oesophageal cancer. Br J Surg. 2018;105(5):502-11. https://doi.org/10.1002/bjs. 10803.

45. van Adrichem EJ, Meulenbroek RL, Plukker JT, Groen H, van Weert E. Comparison of two preoperative inspiratory muscle training programs to prevent pulmonary complications in patients undergoing esophagectomy: a randomized controlled pilot study. Ann Surg Oncol. 2014;21(7):2353-60. https://doi.org/10.1245/s1 0434-014-3612-y.

46. Christensen JF, Simonsen C, Banck-Petersen A, et al. Safety and feasibility of preoperative exercise training during neoadjuvant treatment before surgery for adenocarcinoma of the gastro-oesophageal junction. BJS Open. 2019;3(1):74-84. https://doi.org/ 10.1002/bjs5.50110.

47. Halliday LJ, Doganay E, Wynter-Blyth VA, Hanna GB, Moorthy $\mathrm{K}$. The impact of prehabilitation on post-operative outcomes in oesophageal cancer surgery: a propensity score matched comparison. J Gastrointest Surg. 2020. https://doi.org/10.1007/ s11605-020-04881-3.

48. Weblin J, Mcwilliams D, Tucker O. Feasibility of implementing prehabilitation in patients undergoing major oesophagogastric cancer resection: a single centre experience. ACPRC $J$. 2017;49:82-94.

49. Cho H, Yoshikawa T, Oba MS, et al. Matched pair analysis to examine the effects of a planned preoperative exercise program in early gastric cancer patients with metabolic syndrome to reduce operative risk: the Adjuvant Exercise for General Elective 
Surgery (AEGES) study group. Ann Surg Oncol. 2014;21(6):2044-50. https://doi.org/10.1245/s10434-013-3394-7.

50. Herrstedt H, Bay ML, Simonsen C, et al. Exercise-mediated improvement of depression in patients with gastro-esophageal junction cancer is linked to kynurenine metabolism. Acta Oncol (Madr). 2019;58(5):579-87. https://doi.org/10.1080/0284186X.2 018.1558371

51. Akiyama Y, Sasaki A, Fujii Y, et al. Efficacy of enhanced prehabilitation for patients with esophageal cancer undergoing esophagectomy. Esophagus. 2021;18(1):56-64. https://doi.org/1 0.1007/s10388-020-00757-2.

52. Dettling DS, van der Schaaf M, Blom RLGM, et al. Feasibility and effectiveness of pre-operative inspiratory muscle training in patients undergoing oesophagectomy: a pilot study. Physiother Res Int. 2013;18(1):16-26. https://doi.org/10.1002/pri.1524.

53. Zylstra JL. Structured exercise during neo-adjuvant chemotherapy in patients with operable adenocarcinoma of the oesophagus and gastro-oesophageal junction. $\mathrm{PhD}$ thesis, John Moore's University, Liverpool. 2020.

54. Jiao J, Fan X, Dang H, Yin J, Wang Q, Zhang G, Fu J. Effects of comprehensive nursing care on recovery of respiratory function after thoracic surgery. Int J Clin Exp Med. 2020;13(7):5328-34.

55. Fagevik-Olsén M, Kjellby Wendt G, Hammerlid E, et al. Effects of a training intervention for enhancing recovery after Ivor-Lewis esophagus surgery: a randomized controlled trial. Scand J Surg. 2017;106(2):116-25. 1457496916655499 .

56. Chen $\mathrm{CCH}, \mathrm{Li} \mathrm{HS}$, Liang JT, et al. Effect of a modified hospital elder life program on delirium and length of hospital stay in patients undergoing abdominal surgery: a cluster randomized clinical trial. JAMA Surg. 2017;152(9):827-34. https://doi.org/10. 1001/jamasurg.2017.1083.

57. Chang Y-L, Tsai Y-F, Hsu C-L, et al. The effectiveness of a nurse-led exercise and health education informatics program on exercise capacity and quality of life among cancer survivors after esophagectomy: a randomized controlled trial. Int J Nurs Stud. 2020;101:103418. https://doi.org/10.1016/j.ijnurstu.2019.103418.

58. O’Neill LM, Guinan E, Doyle SL, et al. The RESTORE randomized controlled trial: impact of a multidisciplinary rehabilitative program on cardiorespiratory fitness in esophagogastric cancer survivorship. Ann Surg. 2018;268(5):747-55. h ttps://doi.org/10.1097/SLA.0000000000002895.

59. van Vulpen JK, Hiensch AE, van Hillegersberg R, et al. Supervised exercise after oesophageal cancer surgery: the PERFECT multicentre randomized clinical trial. $\mathrm{Br} J$ Surg. 2021;108(7):786-96. https://doi.org/10.1093/bjs/znab078.

60. Fagevik Olsén M, Wennberg E, Johnsson E, et al. Randomized clinical study of the prevention of pulmonary complications after thoracoabdominal resection by two different breathing techniques. Br J Surg. 2002;89(10):1228-34. https://doi.org/10.1046/ j.1365-2168.2002.02207.x.

61. Akiyama Y, Iwaya T, Endo F, et al. Effectiveness of intervention with a perioperative multidisciplinary support team for radical esophagectomy. Support Care Cancer. 2017;25(12):3733-9. htt ps://doi.org/10.1007/s00520-017-3801-x.

62. Jianjun W, Xing W, Guozhong Y, Chuming Z, Jiang Y. Application of exercised-based pre-rehabilitation in perioperative period of patients with gastric cancer. Open Med (Warsaw, Poland). 2019;14:875-82. https://doi.org/10.1515/med-20190103.

63. Nakamura M, Iwahashi M, Nakamori M, et al. An analysis of the factors contributing to a reduction in the incidence of pulmonary complications following an esophagectomy for esophageal cancer. Langenbeck's Arch Surg. 2008;393(2):127-33.

64. van Egmond MA, Engelbert RHH, Klinkenbijl JHG, van Berge Henegouwen MI, van der Schaaf M. Physiotherapy with telerehabilitation in patients with complicated postoperative recovery after esophageal cancer surgery: feasibility study. $J$ Med Internet Res. 2020;22(6):e16056. https://doi.org/10.2196/16056.

65. Wang W, Liu Q, Yu Y, et al. Hand-assisted sputum excretion can effectively reduce postoperative pulmonary complications of esophageal cancer. Ann Palliat Med. 2020;9(6):3721-30. https://d oi.org/10.21037/apm-20-1267.

66. Simonsen C, Thorsen-Streit S, Sundberg A, et al. Effects of highintensity exercise training on physical fitness, quality of life and treatment outcomes after oesophagectomy for cancer of the gastro-oesophageal junction: PRESET pilot study. BJS Open. 2020;4(5):855-64. https://doi.org/10.1002/bjs5.50337.

67. Lunardi AC, Cecconello I, Celso F, et al. Postoperative chest physical therapy prevents respiratory complications in patients undergoing esophagectomy. Rev Bras Fisioter. $2011 ; 15(2): 160-5$.

68. Lococo F, Cesario A, Sterzi S, et al. Rationale and clinical benefits of an intensive long-term pulmonary rehabilitation program after oesophagectomy: preliminary report. Multidiscip Respir Med. 2012;7(2):21. https://doi.org/10.1186/2049-6958-721.

69. Vats N. Effect of deep breathing exercises and incentive spirometry in the prevention of post operative pulmonary complications in the patients of cancer esophagus undergoing esophagectomy. Indian $J$ Physiother Occup Ther. 2009;3(3):60-7.

70. Ljungqvist $\mathrm{O}$, Scott M, Fearon KC. Enhanced recovery after surgery: a review. JAMA Surg. 2017;152(3):292-8. https://doi. org/10.1001/jamasurg.2016.4952.

71. Melnyk M, Casey RG, Black P, Koupparis AJ. Enhanced recovery after surgery (ERAS) protocols: time to change practice? Can Urol Assoc J. 2011;5(5):342-8. https://doi.org/10. 5489/cuaj.11002.

72. Nicholson A, Lowe MC, Parker J, Lewis SR, Alderson P, Smith AF. Systematic review and meta-analysis of enhanced recovery programmes in surgical patients. Br J Surg. 2014;101(3):172-88. https://doi.org/10.1002/bjs.9394.

73. Carli F, Zavorsky GS. Optimizing functional exercise capacity in the elderly surgical population. Curr Opin Clin Nutr Metab Care. 2005;8(1):23-32.

74. Hijazi Y, Gondal U, Aziz O. A systematic review of prehabilitation programs in abdominal cancer surgery. Int $J$ Surg. 2017;39:156-62. https://doi.org/10.1016/j.ijsu.2017.01.111.

75. West MA, Wischmeyer PE, Grocott MPW. Prehabilitation and nutritional support to improve perioperative outcomes. Curr Anesthesiol Rep. 2017;7(4):340-9. https://doi.org/10.1007/s4014 0-017-0245-2.

76. Durrand J, Singh SJ, Danjoux G. Prehabilitation. Clin Med. 2019;19(6):458-64. https://doi.org/10.7861/clinmed.2019-0257.

77. Li C, Carli F, Lee L, et al. Impact of a trimodal prehabilitation program on functional recovery after colorectal cancer surgery: a pilot study. Surg Endosc. 2013;27(4):1072-82. https://doi.org/10. 1007/s00464-012-2560-5.

78. Pouwels S, Fiddelaers J, Teijink JAW, Ter Woorst JF, Siebenga J, Smeenk FWJM. Preoperative exercise therapy in lung surgery patients: a systematic review. Respir Med. 2015;109(12):1495-504. https://doi.org/10.1016/j.rmed.2015.08. 009.

79. Valkenet K, van de Port IGL, Dronkers JJ, de Vries WR, Lindeman E, Backx FJG. The effects of preoperative exercise therapy on postoperative outcome: a systematic review. Clin Rehabil. 2011;25(2):99-111. https://doi.org/10.1177/ 0269215510380830 .

80. Fagevik Olsén M, Larsson M, Hammerlid E, Lundell L. Physical function and quality of life after thoracoabdominal oesophageal 
resection. Results of a follow-up study. Dig Surg. 2005;22(1-2):63-8. https://doi.org/10.1159/000085348.

81. Lagergren P, Avery KNL, Hughes R, et al. Health-related quality of life among patients cured by surgery for esophageal cancer. Cancer. 2007;110(3):686-93. https://doi.org/10.1002/cncr.22833.

82. Markar SR, Zaninotto G, Castoro C, et al. Lasting symptoms after esophageal resection (LASER): European multicenter cross-sectional study. Ann Surg. Epub 17 Nov 2020. https://doi.org/10. 1097/SLA.0000000000003917

83. Djärv T, Lagergren J, Blazeby JM, Lagergren P. Long-term health-related quality of life following surgery for oesophageal cancer. Br J Surg. 2008;95(9):1121-6. https://doi.org/10.1002/b js.6293.
84. Avery KNL, Metcalfe C, Barham CP, Alderson D, Falk SJ, Blazeby JM. Quality of life during potentially curative treatment for locally advanced oesophageal cancer. $\mathrm{Br} \quad J \quad$ Surg. 2007;94(11):1369-76. https://doi.org/10.1002/bjs.5888.

85. Yu W, Park KB, Chung HY, Kwon OK, Lee SS. Chronological changes of quality of life in long-term survivors after gastrectomy for gastric cancer. Cancer Res Treat. 2016;48(3):1030-6. http s://doi.org/10.4143/crt.2015.398.

Publisher's Note Springer Nature remains neutral with regard to jurisdictional claims in published maps and institutional affiliations. 